\title{
The Lipopolysaccharide Lipid A Long-Chain Fatty Acid Is Important for Rhizobium leguminosarum Growth and Stress Adaptation in Free-Living and Nodule Environments
}

\author{
Dianna V. Bourassa, ${ }^{1,3}$ Elmar L. Kannenberg, ${ }^{1}$ D. Janine Sherrier, ${ }^{2}$ R. Jeffrey Buhr, ${ }^{3}$ and \\ Russell W. Carlson ${ }^{1}$ \\ ${ }^{1}$ Complex Carbohydrate Research Center, University of Georgia, Athens 30602, U.S.A.; ${ }^{2}$ Department of Plant and Soil Sciences \\ and Delaware Biotechnology Institute, University of Delaware, Newark 19711, U.S.A.; and ${ }^{3}$ U.S. National Poultry Research \\ Center, Agricultural Research Service, United States Department of Agriculture, Athens, GA 30605, U.S.A.
}

Accepted 4 January 2017.

\begin{abstract}
Rhizobium bacteria live in soil and plant environments, are capable of inducing symbiotic nodules on legumes, invade these nodules, and develop into bacteroids that fix atmospheric nitrogen into ammonia. Rhizobial lipopolysaccharide (LPS) is anchored in the bacterial outer membrane through a specialized lipid A containing a very long-chain fatty acid (VLCFA). VLCFA function for rhizobial growth in soil and plant environments is not well understood. Two genes, acpXL and $l p x X L$, encoding acyl carrier protein and acyltransferase, are among the six genes required for biosynthesis and transfer of VLCFA to lipid A. Rhizobium leguminosarum mutant strains acpXL, acpXL $L^{-} / l p x X L^{-}$, and $l p x X L^{-}$were examined for LPS structure, viability, and symbiosis. Mutations in acpXL and $\operatorname{lpxXL}$ abolished VLCFA attachment to lipid A. The acpXL mutant transferred a shorter acyl chain instead of VLCFA. Strains without $l p x X L$ neither added VLCFA nor a shorter acyl chain. In all strains isolated from nodule bacteria, lipid $A$ had longer acyl chains compared with laboratory-cultured bacteria, whereas mutant strains displayed altered membrane properties, modified cationic peptide sensitivity, and diminished levels of cyclic $\beta$-glucans. In pea nodules, mutant bacteroids were atypically formed and nitrogen fixation and senescence were affected. The role of VLCFA for rhizobial environmental fitness is discussed.
\end{abstract}

Rhizobia are gram-negative bacteria that are capable of thriving in both soil and plant environments. Each of these environments presents different challenges for bacterial growth, reproduction, and persistence. For example, in the soil, the bacteria can encounter drastic and rapid variations in temperature and humidity, such as drought or flooding, and competition with other microorganisms for nutrients, e.g., for plant exudates. In planta environments are considered more stable but can vary considerably depending on the bacterial location, e.g., whether they are located extra- or intracellularly in plant hosts.

Corresponding author: D. V. Bourassa; E-mail: DVB0006@auburn.edu

*The $\boldsymbol{e}$-Xtra logo stands for "electronic extra" and indicates that eight supplementary figures and one supplementary table are published online.

๑) 2017 The American Phytopathological Society
Legume plant environments are of particular interest. On legume roots, rhizobia can induce a new plant organ, the symbiotic root nodule. Rhizobia invade and form persistent infections in nodule tissues and within cells, ultimately differentiating into bacteroids that fix atmospheric nitrogen into ammonia provided to the host-specific plant (Gage 2004; Long 2001; Murray 2011). To survive in changing extra- and intracellular plant micro-environments, rhizobia must be able to adapt to the varying conditions in these environments and circumvent plant defense responses.

Both soil and plant environments are considered stressful for the bacteria (Vriezen et al. 2007), and adaptations in the rhizobial cell envelope and surface are of critical importance for rhizobial survival under varying environmental conditions (Ferguson et al. 2005; Jones et al. 2007). Despite this critical importance, the role of the various bacterial cell-envelope components for bacterial cell adaptations is poorly understood, e.g., the unknown role of Rhizobium leguminosarum lipopolysaccharide (LPS) for bacterial soil and in planta survival. The LPS is the major component of the outer leaflet of the rhizobial outer membrane and consists of three main moieties, $O$-chain polysaccharide (OPS), core (outer and inner), and the lipid A. In comparison with lipid A from other gram-negative bacteria, $R$. leguminosarum lipid A has several distinguishing features, including i) the absence of two phosphate groups typically found on the 1 - and $4^{\prime}$ positions of the glucosamine $(\mathrm{GlcN})$ disaccharide lipid A backbone, ii) the addition of a galacturonic acid to the $4^{\prime}$ position once the phosphate has been removed, iii) the oxidation of the proximal glucosaminosyl residue to 2-aminogluconic acid (GlcNonate), and iv) a very long-chain fatty acid (VLCFA), 27-hydroxyoctacosanoate, linked as an acyloxyacyl ester to the $\beta$-hydroxyl group of the $\beta$-hydroxyacyl chain at the $2^{\prime}$ position and a $\beta$-hydroxybutyrate modification of the 27-hydroxyl group of the VLCFA (Raetz et al. 2007; Ramadas Bhat et al. 1994) (Fig. 1A).

The importance of the VLCFA for lipid A functioning is only partially understood. As the VLCFA attached to lipid A has been found in most Rhizobiaceae species and also in a number of intracellular pathogens such as members of genera Brucella, Bartonella, and Legionella (Corbel 1997; Ramadas Bhat et al. 1991; Zähringer et al. 1995), its presence suggests important functions in bacterial host infections, regardless of whether the interactions are mutualistic or pathogenic. VLCFA has been shown to mediate LPS and lipid A anchoring to the outer 
membrane (Brown et al. 2011), and it may also have functions in outer membrane stability, conferring stress tolerance and adaptation during infection processes. Located in the outer leaflet of the outer gram-negative cell membrane, the VLCFA attached to lipid A seems ideally suited to mediate these functions, as it is likely to span the entire outer membrane.

The biosynthesis and addition of the VLCFA to the LPS lipid A requires a gene region encoding an acyl carrier protein (ACP) $(a c p X L)$, fatty acid synthesis proteins ( fabF $1 X L$ and $f a b F 2 X L)$, $\beta$-hydroxyacyl-ACP dehydratase (fabZXL), an alcohol dehydrogenase $(a d h A 2 X L)$, and an acyltransferase (lpxXL) (Fig. 1B). Homologs of this gene region are present in most VLCFAcontaining bacteria, including members of the Rhizobiaceae as well as in the above-mentioned pathogens (Ardissone et al. 2011; Brown et al. 2011; Colonna-Romano et al. 1990; Haag et al. 2009; Manterola et al. 2005; Sharypova et al. 2003; Vedam et al. 2003). A number of mutants encoding defects in this gene region have been constructed in one or both acpXL or lpxXL both of $R$. leguminosarum, Sinorhizobium meliloti, and Rhizobium sp. strain NGR234 (Ardissone et al. 2011; Brown et al. 2011; Haag et al. 2009; Sharypova et al. 2003; Vedam et al. 2003); all were devoid of the lipid A VLCFA, showing that the biosynthesis of VLCFA-containing lipid $\mathrm{A}$ is dependent on acpXL and lpxXL.

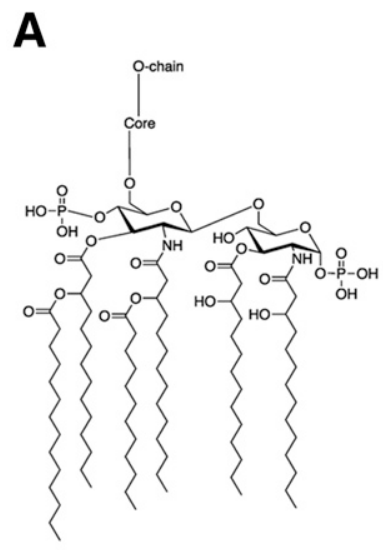

Escherichia coli

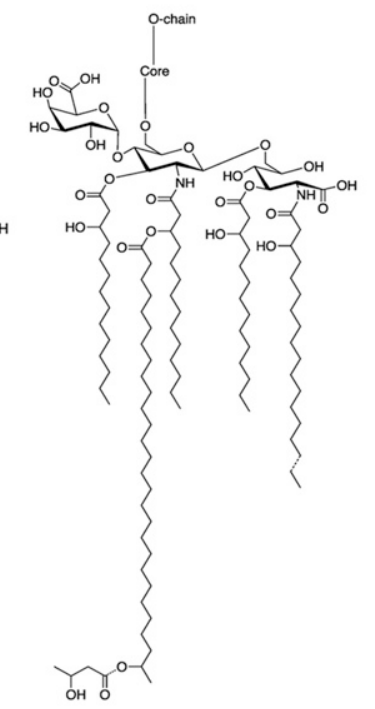

Rhizobium leguminosarum

B

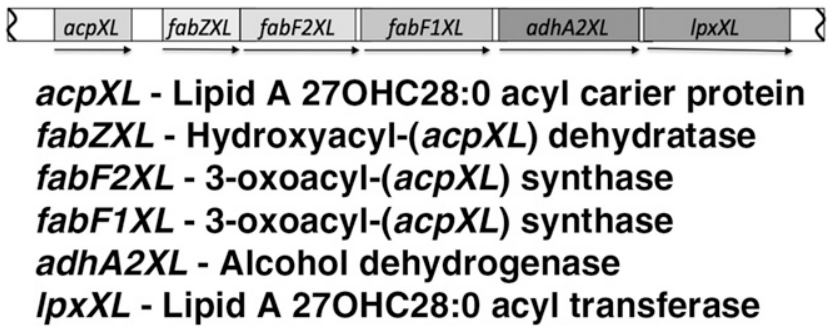

Fig. 1. A, Structures of lipid A from Escherichia coli and Rhizobium leguminosarum, demonstrating structural differences. In particular, note the very long-chain fatty acid (VLCFA) of the $R$. leguminosarum lipid A. B, Schematic of the gene region present in $R$. leguminosarum required for the biosynthesis of VLCFA onto the acyl carrier protein and transfer to the lipid A during lipopolysaccharide biosynthesis.
However, the functional importance of the VLCFA for cellenvelope stability and bacterial infectivity is still elusive for a number of reasons. First, various rhizobial species encoding a mutated acpXL gene exhibit a variable range of phenotypic impairments that are host dependent (Ardissone et al. 2011; Ferguson et al. 2005; Haag et al. 2009; Vedam et al. 2006). This perhaps indicates differing or multiple functions in the various legume host plants. Second, mutants of $R$. leguminosarum and $S$. meliloti lacking AcpXL were devoid of the VLCFA in their lipid A and substitute the VLCFA with a palmitoyl residue in their lipid A (Sharypova et al. 2003; Vedam et al. 2003), obscuring the phenotype that lacks any acyl chain at this position. Third, previous work also demonstrated partial restoration of VLCFA to the lipid A from bacteroids derived from acpXL mutants of R. leguminosarum and S. meliloti (Haag et al. 2009; Sharypova et al. 2003; Vedam et al. 2006), a still unexplained observation. Finally, in most legume hosts, mutants devoid of AcpXL showed effective but developmentally delayed phenotypes, e.g., pea or alfalfa (Haag et al. 2009; Vedam et al. 2004). Comparing the mutant bacteria used to inoculate the host plants with isolates from the developed nodules revealed modified stress-resistant properties of the bacterial isolates after the plant passage, perhaps indicating that the symbiotic host environments select rhizobial variants capable of delayed but effective symbiosis (Vedam et al. 2004).

Taken together, the function of the lipid A VLCFA is, despite past research efforts, not well understood and warrants additional analysis. The scope of this work was, therefore, to assess, in R. leguminosarum-pea symbiosis, the function of the lipid A VLCFA in a number of $R$. leguminosarum mutants (i.e., an ACP acp $X L^{-}$mutant, an acyl transferase $l p x X \mathrm{~L}^{-}$mutant, an acpXL lpxX $X L^{-}$double mutant, as well as in their respective ex-nodule $[\mathrm{ExN}]$ mutant derivatives, i.e., isolates of each mutant obtained from pea nodules). In addition, we aimed to determine the lipid A structures from all LPS isolated from free-living, symbiotic, and nodule isolates for these strains and correlate this with their symbiotic and stress-tolerance phenotypes (i.e., nodule formation and resistance to salt, detergent, and the antibiotic polymyxin B [PmxB]). Both acpXL and lpxXL mutants did not add VLCFA to lipid $\mathrm{A}$. In the acpXL mutant, a shorter acyl chain was transferred in place of VLCFA. However, in strains without $\operatorname{lp} x X L$, neither VLCFA nor a shorter acyl chain was added. For both parent and mutant strains, nodule bacteroids had LPS with longer acyl chains than laboratory-cultured bacteria. The acpXL and lpxXL mutations had altered membrane stability properties, altered sensitivity to cationic peptides, and diminished levels of the osmoprotective cyclic $\beta$-glucans. When the host plant (Pisum sativum L., pea) was inoculated with parent or mutant strains, mutant bacteroids formed atypical irregular branched structures with multiple bacteroids per symbiosome. Mutant bacteroids were not packed as tightly in nodule plant cells and were senescing earlier than the wild-type rhizobia. Nitrogen fixation was also detrimentally affected.

\section{RESULTS}

\section{Construction of $R$. leguminosarum lipid A synthesis-impaired mutants.}

Mutants impaired in lipid A biosynthesis were constructed by homologous recombination mutagenesis in strain $R$. leguminosarum bv. viciae 3841 (Rlv3841), replacing one or both of the functional wild-type genes acpXL and lpxXL with mutated inactive gene derivatives (i.e., an acpXL::kan [Vedam et al. 2003] and a lpxXL::gent derivative [Supplementary Fig. S1]). To our surprise, multiple attempts to create an $l p x X L^{-}$mutant in the Rlv3841 background consistently failed. However, using the existing Rlv22 mutant 
(a derivative of Rlv3841 with the kan cassette in acpXL [Vedam et al. 2003]) as recipient strain, several $a c p X L^{-}$lpxXL double mutants were isolated and strain EL196 was chosen. The double mutant also allowed for the construction of an "effective $l p x X L^{-}$" mutant, namely, strain EL197, through partial complementation of strain EL196 with cloned parent acpXL. For the construction of the effective $l p x X L^{-}$strain EL197, plasmid pVV5, harboring the parent acpXL (Vedam et al. 2003), was mobilized into EL196 to complement the chromosomal acpXL::kan gene mutation. The pVV5 plasmid was predicted to replicate at a low to moderate copy number of five to 30 copies (Buch et al. 2010; Khan et al. 2008; Kovach et al. 1995). The various constructs (Rlv22, EL196, EL197, EL198) were genetically verified through polymerase chain reaction (PCR) amplification of indicative fragments, using gene- and construct-specific primers (Supplementary Fig. S2), and ertr functionally verified with strain EL198 (i.e., EL196 pSSB-1). Plasmid pSSB-1 carries the cloned whole VLCFA-related gene region, including acpXL and $\operatorname{lpx} X L$, complementing strain EL196 back to a wild-type phenotype.

\section{LPS and lipid A isolation and characterization of rhizobia.}

LPSs were isolated by phenol-water extraction from freeliving bacteria, nodule bacteria and bacteroids, and ExN isolates of wild-type and mutant strains. After phenol-water extraction and phase separation, the bulk of the LPSs $(>90 \%$ by weight) from laboratory-cultured bacteria and from nodule bacteria and bacteroid preparations was found in the water layer. The LPSs from laboratory-cultured parent strain Rlv3841 showed, after separation on sodium deoxycholate-polyacrylamide gel electrophoresis (DOC-PAGE) gels (Fig. 2), the well-known LPS banding pattern of LPS I and LPS II (Fig. 2, panel 1, lane 1) (Kannenberg and Carlson 2001). The comparison of this parent type LPS with the LPS from the laboratory-cultured $a c p X L^{-}$mutant
Rlv22 showed a similar banding pattern as observed for Rlv3841 but with all bands slightly shifted to a lower molecular weight. This small shift in the banding pattern has already been reported (Vedam et al. 2003) and is expected to be due to the loss of the VLCFA from the lipid A (Fig. 2, panel 1, lane 2). The LPS from strain EL196 (acpXL $L^{-}$lpxXL $L^{-}$double mutant) and its ExN isolate resembled each other and were very similar to the LPS banding pattern from laboratory-cultured Rlv22, including the slight shift to lower molecular weight LPS forms compared with Rlv3841 LPS. The LPS from strain EL197 (lpxXL ) also displayed a similar banding pattern to Rlv22 and EL196 LPS, including the shift to lower molecular weight LPSs compared with Rlv3841 LPS.

Since, for parent strain Rlv3841, nodule-dependent LPS modifications have been reported that involve a shift to higher molecular weight LPS forms (Kannenberg and Carlson 2001), it was of particular interest to compare the various wild and mutant-type LPSs from laboratory cultures with those isolated from nodule bacteria and bacteroids. The LPSs from nodule bacteria and bacteroids of strains Rlv22 and EL196 contained, instead of the usual LPS I ladder pattern, only two prominent higher molecular weight LPS I bands (Fig. 2, third lanes in panels 1 and 2). In addition, there were either no detectable or only minimally detectable levels of LPS II in these nodule bacteria and bacteroid-derived LPS fractions, which, together, is suggestive of conditional, nodule-dependent expression of LPS forms. Additionally, comparison of the LPSs from laboratorycultured ExN Rlv22 and ExN EL196 with the LPSs from the respective laboratory-cultured bacteria showed largely the same banding pattern (Fig. 2, fourth lanes in panels 1 and 2), indicating that the modifications are transient and host dependent.

In contrast, the LPS from strain EL197 nodule bacteria and bacteroids had a banding pattern more similar to parent Rlv3841 nodule bacteria and bacteroid LPS in that it contained the various

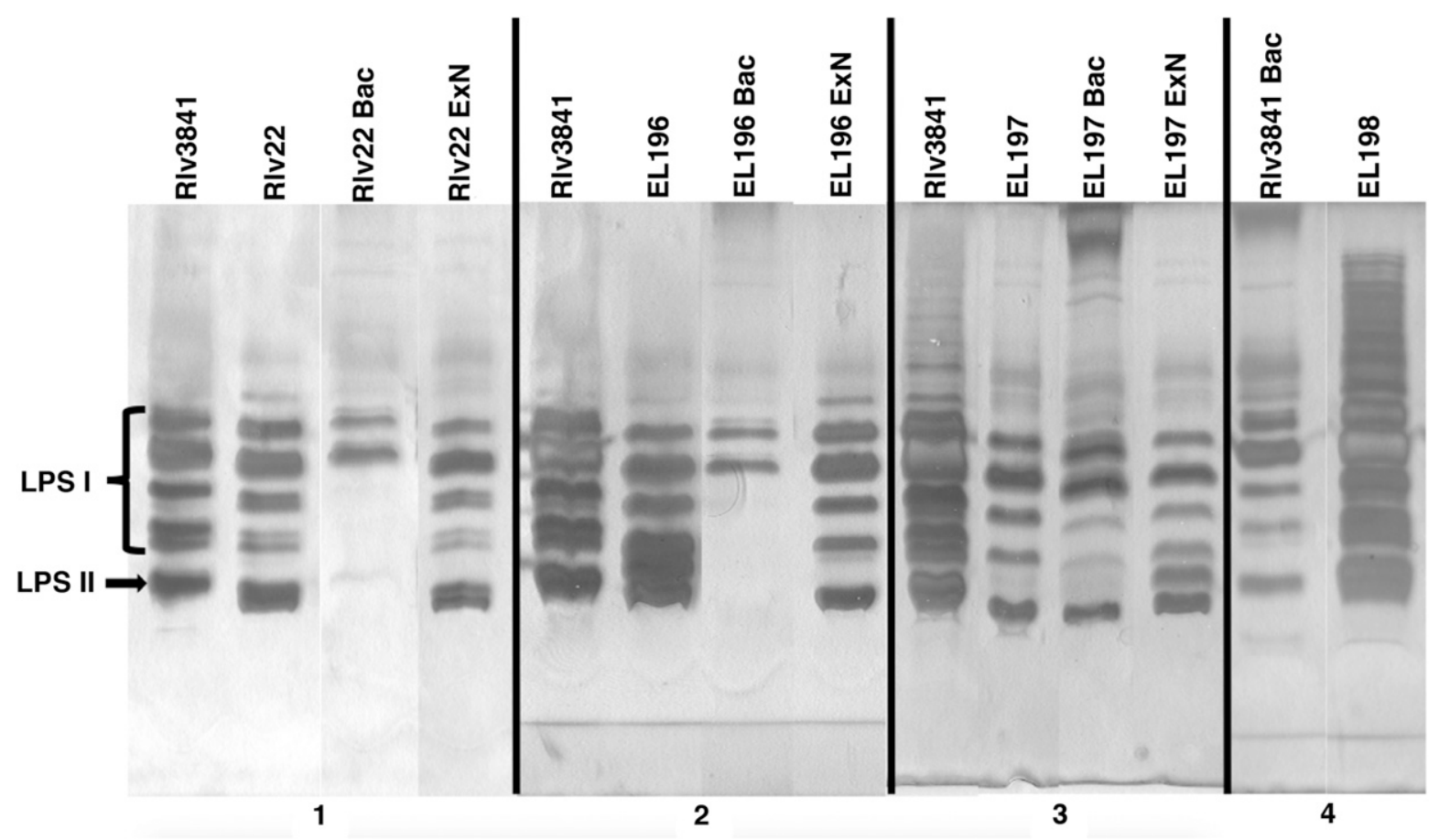

Fig. 2. Alcian blue/silver-stained sodium deoxycholate-polyacrylamide electrophoresis gels. Separation of lyophilized lipopolysaccharide (LPS) fractions after hot phenol/water extraction and purification of the water-soluble LPSs. Section 1 shows separation of Rlv3841 free-living LPS compared with Rlv22 (i.e., Rlv3841 acpXL::km) free-living, bacteroid (Rlv22 Bac), and ex-nodule (ExN) (Rlv22 ExN) LPS. Section 2 shows separation of Rlv3841 free-living LPS compared with EL196 (i.e., Rlv3841 acpXL::km, lpxXL::gm) free-living, bacteroid, and ExN LPS. Section 3 shows separation of Rlv3841 free-living LPS compared with EL197 (i.e., Rlv3841 acpXL::km, lpxXL::gm, pVV5acpXL) free-living, bacteroid, and ExN LPS. Section 4 shows separation of Rlv3841 bacteroid LPS compared with EL198 (complemented double mutant) free-living LPS. In each sample well, $1 \mu \mathrm{g}$ of dry weight of lyophilized LPS material from the water layer of phenol/water extractions in $1 \mu \mathrm{l}$ of loading buffer was added. 
LPS I bands to some degree but, also, a shift toward higher molecular weight LPS I bands and a LPS II than observed for Rlv3841 (Kannenberg and Carlson 2001). In mutants without the ACP AcpXL, i.e., Rlv22 and EL196, almost exclusively, two uniform, higher molecular weight forms of LPS I are formed; in contrast, mutant bacteria and bacteroids of EL197 (i.e., lpxXL express LPS forms with a variety of OPS chain lengths as well as LPS II without OPS (Fig. 2, third lane in panel 3 and first lane in panel 4). These LPS forms are very similar to the Rlv3841 parent bacteroid LPS. This also suggests that AcpXL can, to a degree, replace LpxXL with regard to the type of LPS observed on DOCPAGE analysis but not the other way around.

Previous research showed that lipid A fatty acid composition can vary due to culture conditions (D'Haeze et al. 2007; Kannenberg and Carlson 2001). To investigate this aspect further, the relative fatty acid compositions of the lipid A isolated from laboratory cultures, nodule bacteria and bacteroids, and laboratory cultures of ExN isolates of strain Rlv3841 and from the set of mutant derivatives involved in lipid A synthesis were investigated (Table 1). In agreement with previous findings, the main fatty acids identified in the different lipid As were C16:0, C18:0, five different 3OH fatty acids (i.e., 3OHC14:0, 3OHC15:0, 3OHC16:0, 3OHC18: 0 , and 3OHC18:1), and the VLCFA 27OHC28:0. Differing results observed in this study as compared with Vedam et al. (2006) for the same $R$. leguminosarum strains (Rlv3841 and Rlv22) may be attributed to differing LPS extraction methods.

The lipid As isolated from laboratory cultures from the mutant strains Rlv22, EL196, and EL197 were devoid of the VLCFA, leading in all three strains to an increase in the percentages of $3 \mathrm{OH}$ fatty acids (from $74 \%$ of the fatty acids in parent strain Rlv3841 to $>95 \%$ in the derived $R$. leguminosarum mutant strains). Interestingly, under laboratory conditions, both C16:0 and C18:0 fatty acids are found only in small amounts $(<2 \%)$ in extracts from all three mutants (Rlv22, EL196, EL197). This was in contrast to nodule conditions in which the relative percentage of $\mathrm{C} 16: 0$ and $\mathrm{C} 18: 0$ fatty acids of the lipid $\mathrm{A}$ greatly increased in strains Rlv22 Bac $\left(a c p X L^{-}\right)$and EL196 Bac $\left(a c p X L^{-} / l p x X L^{-}\right)$, concomitantly with a strong decrease in $3 \mathrm{OH}$ fatty acids, in particular in the $3 \mathrm{OH} \mathrm{C14:0.} \mathrm{However,} \mathrm{the} \mathrm{strong}$ increase of C16:0 and C18:0 was not found with lipid As derived from nodule bacteria from strain EL197 Bac $\left(\right.$ lpxXL $\left.L^{-}\right)$and the total amount of $3 \mathrm{OH}$ fatty acids stayed almost as high as found in laboratory culture (Table 1). A noticeable adaptation, however, also took place within the mix of $3 \mathrm{OH}$ fatty acids of this EL197 strain; the 3OHC14:0 was decreased, while 3OHC18: 0 was increased. Taken together, these findings indicate that lipid A fatty acid composition is possibly fine-tuned for functioning under changing growth conditions and that LpxXL may be involved in C16:0 and C18:0 fatty acid transfer to lipid A, primarily under nodule conditions.

Interestingly, 3\% of the total fatty acids of EL197 bacteroid lipid A were VLCFA. Although VLCFA was found in the EL197 lipid A preparation, there was no lipid A containing VLCFA detected, using matrix-assisted laser desorptionionization time of flight mass spectrometry (MALDI-TOF MS) analysis (described further below), i.e., all ions observed were consistent with lipid A species that lacked the VLCFA. It is possible that VLCFA AcpXL may have been isolated during the phenol-water extraction and, therefore, the observed VLCFA may not be part of the lipid A. The larger amounts of VLCFA AcpXL may be present since this strain contains multiple copies of plasmid pVV5, which carries the acpXL gene.

\section{Chain-length shifts in lipid-A structures from RIv3841 laboratory-cultured bacteria and from nodule bacteria and bacteroids.}

To gain further insight into lipid A structure, preparations isolated from laboratory-cultured bacteria and nodule bacteria and bacteroids were also analyzed by MALDI-TOF MS (Table 2; Figs. 3 and 4, Supplementary Figs. S3, S4, and S5). Figure 4 shows the structures I.A, I.B, II, III.A, III.B, IV, V.A, and V.B, predicted from the MALDI-TOF MS spectra and described in Supplementary Table S1. Each lipid A structure is heterogeneous with regard to one or both the fatty acid chain length or proximal GlcN structure, creating a cluster of ions this way.

As shown in Figure 3, lipid A from the laboratory-cultured parent strain Rlv3841 has four major clusters of ions consistent with structures I.A, I.B, II, III.A, III.B, and IV. The VLCFA is attached to structures I.A and I.B with either GlcN (I.A) or GlcNonate (I.B) as proximal sugar and to structure II, which is

Table 1. Relative fatty acid compositions (major constituents only) of lipid A from Rhyzobium leguminosarum Rlv3841, Rlv22, EL196, and EL197 free-living bacteria, bacteroids $(\mathrm{Bac})$, and ex-nodule $(\mathrm{ExN})$ bacteria

\begin{tabular}{|c|c|c|c|c|c|c|c|c|}
\hline \multirow[b]{3}{*}{ Strain } & \multicolumn{8}{|c|}{ Fatty acid percentages $^{w}$} \\
\hline & \multirow[b]{2}{*}{ C16:0 $0^{x}$} & \multirow[b]{2}{*}{ C18:0 } & \multicolumn{5}{|c|}{$\mathbf{3 O H}$} & \multirow{2}{*}{$\frac{27 \mathrm{OH}}{\mathrm{C} 28: 0}$} \\
\hline & & & C14:0 & C15:0 & C16:0 & C18:0 & C18:1 & \\
\hline Rlv3841 & 4 & 5 & 46 & 2 & 9 & 13 & 4 & 16 \\
\hline Rlv3841 Bac & 8 & 9 & 20 & 4 & 4 & 8 & 7 & 41 \\
\hline Rlv3841 ExN & 6 & 12 & 37 & 2 & 7 & 9 & 2 & 25 \\
\hline Rlv22 & 2 & $\mathrm{ND}^{\mathrm{y}}$ & 57 & 7 & 13 & 18 & 1 & ND \\
\hline Rlv22 Bac & 14 & 11 & 36 & 12 & 6 & 9 & 11 & ND \\
\hline Rlv22 ExN & 4 & 4 & 43 & 4 & 13 & 29 & 4 & ND \\
\hline EL196 & 1 & 1 & 57 & 5 & 12 & 22 & 3 & ND \\
\hline EL196 Bac & 21 & 26 & 26 & 11 & 5 & 5 & 6 & ND \\
\hline EL196 ExN & 2 & 14 & 32 & 10 & 11 & 29 & 2 & ND \\
\hline EL197 & 1 & 1 & 53 & 5 & 12 & 24 & 4 & ND \\
\hline EL197 Bac & 1 & 3 & 30 & 4 & 12 & 41 & 6 & $3^{z}$ \\
\hline EL197 ExN & 3 & 17 & 46 & 9 & 9 & 15 & 2 & ND \\
\hline
\end{tabular}

\footnotetext{
${ }^{\mathrm{w}}$ Fatty acid percentages are calculated based on the ratios of gas chromatography area values.

${ }^{x}$ Small amounts of C16:0 and C18:0, in mutants that lack acpXL but not lpxXL can be due to the fact that lpxXL can add these fatty acids, to a small degree, from other acp-fatty acid substrates. However, a small portion of these two fatty acids could also be due to slight contamination by phospholipids. However, the large increases in these fatty acids in the EL196 and Rlv22 bacteroid lipopolysaccharide preps are unlikely to be explained completely by phospholipid contamination.

${ }^{\mathrm{y}} \mathrm{ND}=$ none detected.

${ }^{\mathrm{z}}$ Very long-chain fatty acid (VLCFA) was present in EL197 bacteroid lipid A preparations; however, this long-chain fatty acid was not attached to the lipid A component. It is a possibility that VLCFA was attached to AcpXL and extracted from the cells during the phenol/water extraction procedure.
} 
missing $3 \mathrm{OHC} 14: 0$ on the three-position of the proximal modified GlcNonate. The loss of this fatty acid is believed, however, to be an artifact of the mild acid hydrolysis procedure used to isolate lipid A (Price et al. 1995); due to elimination of the fatty acyl residue and production of a proximal 2-ene-GlcNono-lactone residue on the lipid A. Thus, structures I and II are due to pentaacylated lipid A species (II being an artifact of I). Structures III.A, III.B, and IV were observed to a lesser extent and are tetraacylated structures that lack the VLCFA. The ions observed for structure III were of the shorter fatty acyl chains (only 1448.1, 1464.0, 1476.1, and 1492.1 $m / z$ ) in comparison with ions observed from the mutants (1447.9, $1463.9,1475.9,1491.9,1513.9,1520.0,1548.0$, and $1577.9 \mathrm{~m} / \mathrm{z})$. Structures III and IV are similar to I and II but lack the VLCFA.

The lipid A from Rlv3841 nodule bacteria and bacteroids also displayed structures I.A, I.B, II, and IV (Fig. 4). However, many of these lipid A structures had a shift toward longer chain fatty acids in each ion cluster. For example, ion $1914.6 \mathrm{~m} / \mathrm{z}$ is a longer fatty acid chain variant of $1886.5 \mathrm{~m} / z$, and ions 2012.7 and $1984.6 \mathrm{~m} / \mathrm{z}$ are longer fatty acid chain variants of ion $1956.5 \mathrm{~m} / \mathrm{z}$. The structures I.A and I.B with the shortest chain lengths (ions 1870.5 and $1886.5 \mathrm{~m} / \mathrm{z}$, respectively) were only observed in the laboratory-cultured parent and not the nodule bacteria or bacteroids. Both the laboratory cultures and nodule bacteria and bacteroid Rlv3841 had the same ions for structure II. Structure III, the tetraacylated lipid A, was observed in laboratory-cultured Rlv3841 only and not in the nodule bacteria or bacteroids. For structure IV (the artifactual elimination product of structure III), Rlv3841 laboratory-cultured lipid A lacked two ions, m/z 1259.9 and 1301.9, that were observed in the bacteroid lipid A. These ions are 16 mass units greater than corresponding structure IV ions, and structures for these ions remain unassigned. However, they could be oxygen adducts of structure IV molecules. The nodule bacteria and bacteroids contained all of the observed ions for variations of structure IV (except for the three with the shortest acyl chain lengths $1173.8,1201.8$, and $1229.9 \mathrm{~m} / \mathrm{z}$ ).

\section{Additional structures and chain-length shifts in lipid A from mutants in laboratory culture versus lipid A from mutant nodule bacteria.}

Laboratory-cultured Rlv22 ( $a c p X L^{-}$) had structures III.A, III. B, IV, and V.B., all of which lack the VLCFA (Table 2; Fig. 3). Structure V is similar to structure I, except that a C16:0 or C18: 0 is added instead of the VLCFA. Based on peak intensity, structure V was less abundant than structures III and IV in the laboratory-cultured bacteria and structure V.A may be present at insufficient levels for detection. The Rlv22 nodule bacteria and bacteroid lipid A showed ion clusters tending toward having longer chain fatty acids. Structure $\mathrm{V}$ with the additional $\mathrm{C} 16: 0$ or C18:0 was also more abundant, i.e., the relative intensity of its ion was greater in the nodule bacteria and bacteroid-derived lipid A sample, as compared with the lipid A from laboratory culture. The proximal-GlcN form of structure III was not observed in Rlv22 nodule bacteria and bacteroid lipid A as was observed for Rlv3841 nodule bacteria. Only the shorter chain ions $(1448.1$ and $1476.1 \mathrm{~m} / \mathrm{z}$ ) were observed for laboratorycultured Rlv22 structure III.A. Rlv22 structure III.B. had two observed ions thought to be sodiated structures that were not present in any other strains, one $(1513.9 \mathrm{~m} / \mathrm{z})$ present only in the laboratory culture and one $(1577.9 \mathrm{~m} / \mathrm{z})$ observed in both laboratory culture and nodule bacteria and bacteroid Rlv22. For structure IV, the laboratory-cultured Rlv22 lacked the ions that are unassigned and may be oxygen adducts of structure IV, while the ions $1273.9 \mathrm{~m} / \mathrm{z}$ and above were observed in the nodule bacteria and bacteroids. The proximal-GlcN form of structure $\mathrm{V}$ was not observed in Rlv22 laboratory culture, and only the ions corresponding to the proximal-GlcNonate form with shorter chain-length structures were observed $(1786.2 \mathrm{~m} / \mathrm{z}$ and below).
EL196 (acpXL-/lpxXL $L^{-}$) and EL197 (effective lpxXL') both had structures III.A, III.B, and IV in both free-living and bacteroid lipid A (Table 2, Fig. 3). EL196 nodule bacteria and bacteroids had structure III.A lipid A with longer chain-length fatty acyl residues (ion 1560.2) than that from the laboratorycultured strain and did not have the ions thought to be sodiated that were observed for Rlv22. The EL196 nodule bacteria and bacteroid lipid A did not have the ions for the predicted shortest chain-length structures that were observed for the laboratory culture $(1173.8$ and $1201.8 \mathrm{~m} / \mathrm{z})$. Neither the laboratory strain nor the bacteroids had the ions for the unassigned structure IV molecules (which could be oxygen adducts). Both laboratorycultured and nodule bacteria and bacteroid EL197 lipid A had all of the observed ions for structure III.A, but, for structure III. $\mathrm{B}$, the nodule bacteria and bacteroid lipid A had an additional ion predicted to have longer acyl chains. EL197 nodule bacteria and bacteroids had ions predicted to be hydroxylated or sodiated in addition to the ions observed for the laboratory culture. Both the EL196 and EL197 bacteroid lipid A were shifted toward longer chain fatty acid structures. Mutation of the $\operatorname{lp} x X L$ gene prevented the addition of the VLCFA as well as substitution of the VLCFA with shorter chain fatty acid. The shift toward longer chain fatty acids from bacteroids in comparison with laboratory-cultured strains is also shown by the fatty acid compositions in which C16:0 and C18:0 percentages increase between laboratory-cultured bacteria and bacteroids while the fatty acid percentages of C14:0 decreased (Table 1).

\section{Increased mutant sensitivities to stressors.}

The sensitivity and resistance of the mutants to stress in vitro was tested by growing the strains in the presence of increased levels of $\mathrm{NaCl}$ (increased osmolarity), in the presence of the detergents sodium dodecyl sulfate (SDS) or DOC (Table 3), and with the cationic peptide antibiotic PmxB (Fig. 5), known to affect gram-negative cell-membrane architecture, thereby inhibiting growth (Teuber and Bader 1976). The mutant strains Rlv22, EL196, and EL197 were all sensitive to $\mathrm{NaCl}$ at $0.5 \%$ in the growth medium, while parent strain Rlv3841 and the fully complemented double mutant EL198 were able to grow at this salt concentration. A related observation was made in attempts to grow the bacteria on media plates supplemented with detergents SDS or DOC. On media containing 0.35 mM SDS, the wild-type strain Rlv3841 grew, while all three mutants Rlv22, EL196, and EL197 were unable to grow at this concentration. Similarly, while the parent Rlv3841 strain was able to grow on DOC plates with up to $3 \mathrm{mM}$ DOC in the medium, mutants Rlv22 and EL196 were considerably more growth-sensitive and stopped growing at $0.76 \mathrm{mM}$ DOC. Mutant EL197 was even more susceptible to DOC than Rlv22 and EL196 and was unable to grow at a concentration of $0.64 \mathrm{mM}$ DOC. An uneven picture emerged in attempts to grow the mutants on PmxB gradient plates; while

Table 2. Lipid A structures of Rhizobium leguminosarum under free-living and nodule growth conditions

\begin{tabular}{lcccccccc}
\hline & \multicolumn{7}{c}{ Lipid A structure $^{\mathbf{z}}$} \\
\cline { 2 - 8 } Strain & I.A & I.B & II & III.A & III.B & IV & V.A & V.B \\
\hline Rlv3841 & + & + & + & + & + & + & - & - \\
Rlv3841 Bac & + & + & + & - & - & + & - & - \\
Rlv22 & - & - & - & + & + & + & + & + \\
Rlv22 Bac & - & - & - & - & + & + & - & + \\
EL196 & - & - & - & + & + & + & - & - \\
EL196 Bac & - & - & - & + & + & + & - & - \\
EL197 & - & - & - & + & + & + & - & - \\
EL197 Bac & - & - & - & + & + & + & - & - \\
\hline
\end{tabular}

$\overline{\mathrm{z}}+$ and - indicate the presence or absence of each lipid A structure by strain. 
Rlv22 and EL196 were more sensitive and displayed diminished growth in comparison with the parent Rlv 3841 and the complemented double mutant EL198 (Fig. 5), mutant EL197 showed the wild-type level of resistance toward PmxB.

Following passage through the plant, it was previously shown that the Rlv22 ExN isolate gained parental levels of tolerance to $\mathrm{NaCl}$, despite being unmodified with regard to acpXL during the plant passage (Vedam et al. 2003). This surprising but unexplained the result was confirmed for Rlv22 ExN and was also found to be true for the ExN isolate of mutant EL196. Similarly to $\mathrm{NaCl}$ salt sensitivity, the Rlv22 ExN and EL196 ExN isolates both showed increased tolerance to SDS and DOC.
However, none of these mutant ExN isolates regained resistance to DOC to the same level as the parent strain or to the complemented double mutant. In contrast to Rlv22 ExN and EL196 ExN, the EL197 ExN isolate did not gain tolerance to $\mathrm{NaCl}$; the EL197 ExN isolate displayed the same level of sensitivity toward salt, SDS, and DOC that was observed with its parent EL197 before plant passage. With regard to PmxB, all three ExN mutant isolates did not exhibit increased tolerance to PmxB, as was observed for SDS, DOC, and $\mathrm{NaCl}$. Moreover, EL197 ExN was found to be more susceptible to PmxB as compared with the parent EL197 strain before the plant passage.
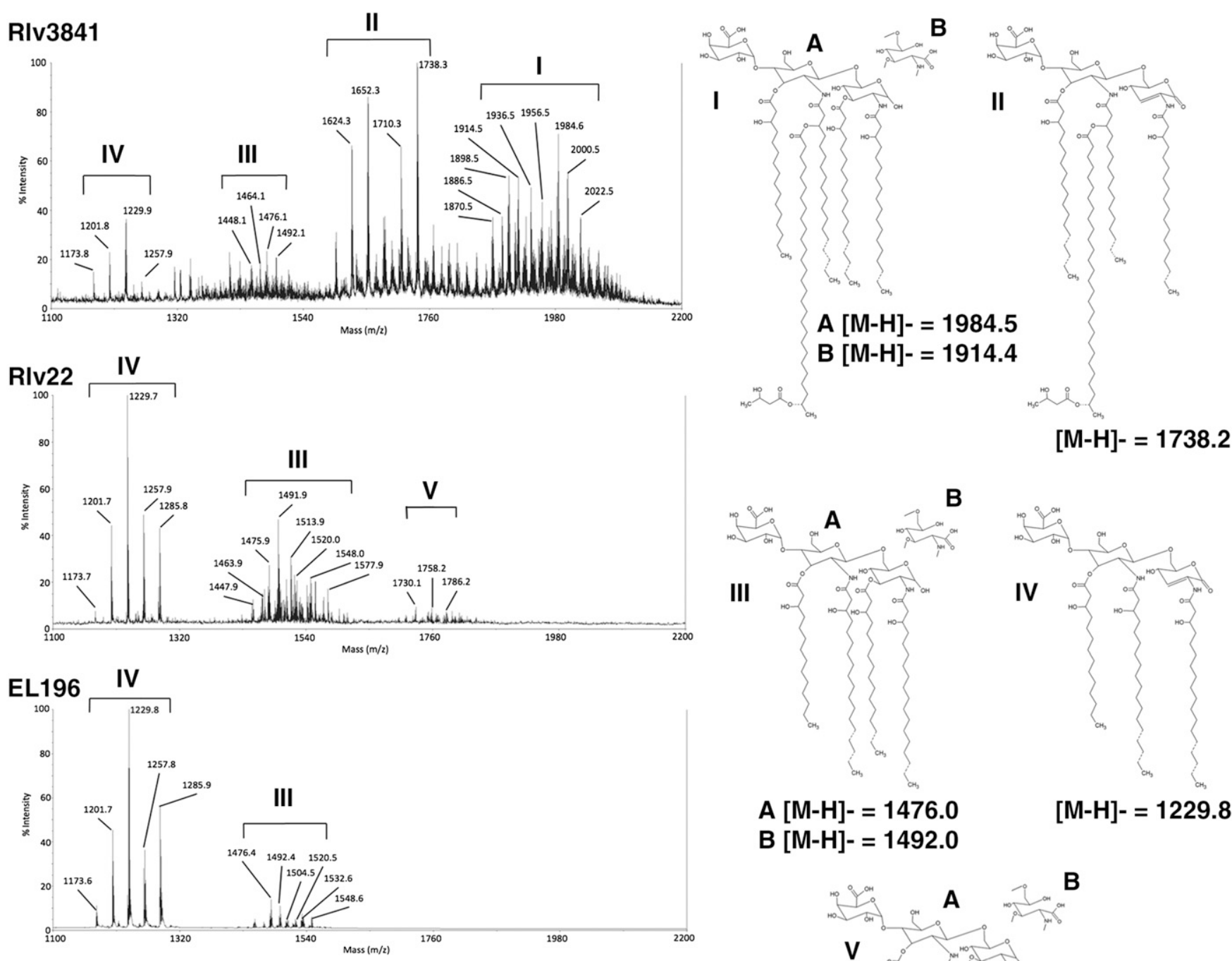

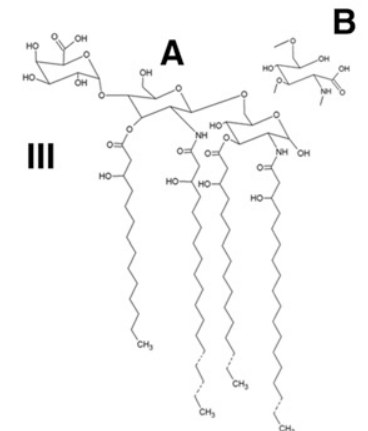

$A[M-H]-=1476.0$
$B[M-H]-=1492.0$

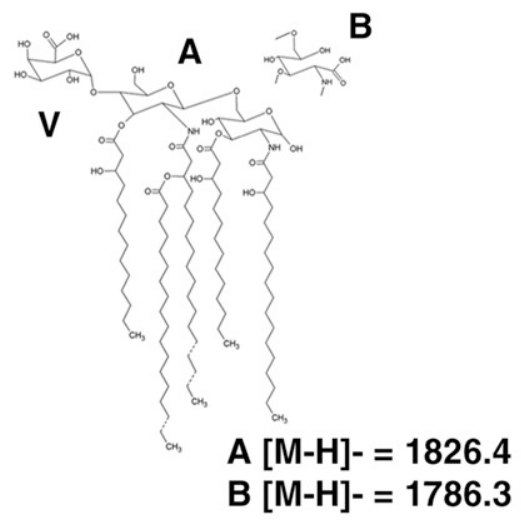

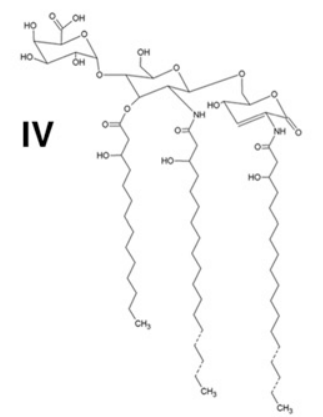

$[\mathrm{M}-\mathrm{H}]-\mathbf{=} 1229.8$

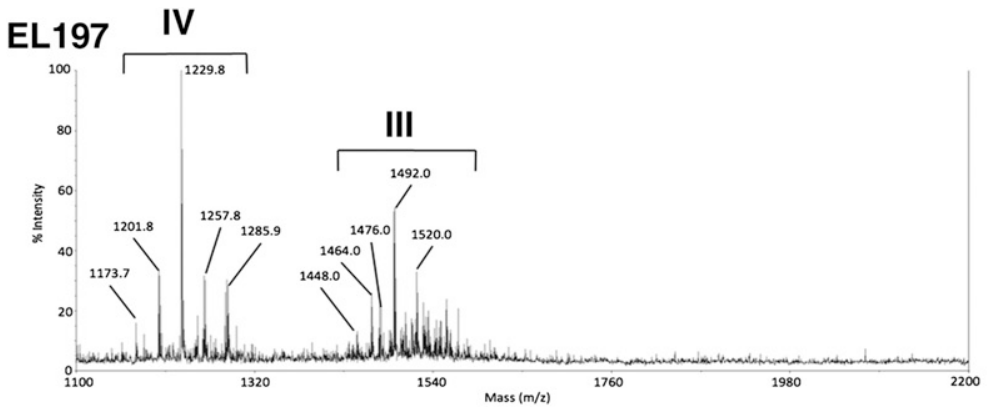

Fig. 3. Matrix-assisted laser desorption-ionization time of flight mass spectrometry (MALDI-TOF MS) spectrum of lipid As isolated from laboratory cultures of strains Rlv3841 (parent), Rlv22 ( $\left.a c p X L^{-}\right)$, EL196 (acpXL $\left.L^{-} / l p x X L^{-}\right)$, and EL197 (lpxXL $L^{-}$) and their proposed lipid A structures deduced from MALDI-TOF MS analysis. Structures I.A, I.B, II, III.A, III.B, and IV were observed in Rlv3841 lipid A. Structures III.A, III.B, IV, V.A, and V.B were observed in Rlv22 lipid A. Structures III.A, III.B, and IV were observed in EL196 and EL197 lipid A. Very long-chain fatty acid (VLCFA) was only observed in the parent strain; Rlv22 was able to substitute a shorter chain fatty acid for the VLCFA; and neither EL196 nor EL197 was able to add VLCFA or the shorter chain fatty acid. 
Decreasing ratios of cyclic $\beta$-glucans from mutants and $\operatorname{ExN}$ parent strains.

$R$. leguminosarum is known to use cyclic $\beta$-glucans for hypoosmotic adaptation and their synthesis is osmoregulated (Breedveld et al. 1990; Griffitts et al. 2008). Thus, the ability of Rlv22 and EL196 to regain resistance to $\mathrm{NaCl}$ and detergents after passage through the plant may have been due to a change in the amount of cyclic $\beta$-glucans found in the periplasm of ExN strain isolates. Since the cyclic $\beta$-glucan is composed of glucose connected by 1,2-glycosidic linkages, 2-linked glucose (2-Glc) levels were determined, to estimate the relative amounts of cyclic $\beta$-glucan present in the parent, the mutants, and their ExN isolates, as described below. The results are shown in Figure 6. Rlv3841 and EL198 laboratory culture bacteria had greater amounts of 2-Glc (2-Glc/Ino ratios of 30.9 and 18.9, respectively) compared with mutants Rlv22 and EL197 (3.4 and 2.1 ratios, respectively). EL196 had a barely detectable amount of 2-Glc (a 0.5 ratio). Only the ExN isolate of Rlv22 showed a modest increase in the relative amount of 2-Glc from laboratory to ExN culture. The EL196 and EL197 ExN isolates were unchanged in their levels of 2-Glc. Interestingly, Rlv3841 and EL198 both displayed a dramatic decrease in the 2-Glc/Ino ratio, i.e., 13- and fourfold decreases, from amounts found in laboratory cultures to ExN derivative cultures, possibly indicating that cyclic $\beta$-glucans may be downregulated in these bacteria during nodule passage. These results imply that the restoration of salt and detergent tolerance in the ExN isolates is unlikely to be caused by an increased production of cyclic $\beta$-glucan. However, the lesser amounts of cyclic $\beta$-glucans observed in Rlv22, EL196, and EL197 could possibly have impacted the ability of those mutants to infect the host. The reason for the decrease in

Table 3. Osmotic tolerance and detergent sensitivity of laboratory-cultured and ex-nodule (ExN) Rhizobium leguminosarum strains $^{\mathrm{z}}$

\begin{tabular}{|c|c|c|c|c|c|c|c|}
\hline \multirow[b]{2}{*}{ Strain } & \multirow{2}{*}{$\frac{\mathrm{NaCl} \%}{0.50}$} & \multicolumn{2}{|c|}{ SDS (mM) } & \multicolumn{4}{|c|}{ DOC $(\mathrm{mM})$} \\
\hline & & 0.35 & 0.52 & 0.64 & 0.76 & 1.00 & 2.00 \\
\hline Rlv3841 & + & + & + & + & + & + & + \\
\hline Rlv3841 ExN & + & + & + & + & + & + & + \\
\hline EL198 & + & + & + & + & + & + & + \\
\hline Rlv22 & - & - & - & + & - & - & - \\
\hline Rlv22 ExN & + & + & - & + & + & - & - \\
\hline EL196 & - & - & - & + & - & - & - \\
\hline EL196 ExN & + & + & - & + & + & - & - \\
\hline EL197 & - & - & - & - & - & - & - \\
\hline EL197 ExN & - & - & - & - & - & - & - \\
\hline
\end{tabular}

${ }^{\mathrm{z}}$ Strains were grown on tryptone-yeast extract plus calcium media for 3 days at $30^{\circ} \mathrm{C}$ with the indicated concentrations of $\mathrm{NaCl}$, sodium dodecyl sulfate (SDS), or sodium deoxycholate (DOC). + and - indicate whether that strain of Rhizobium leguminosarum was able to grow on the media.

\section{RIv3841 Laboratory Cultured}
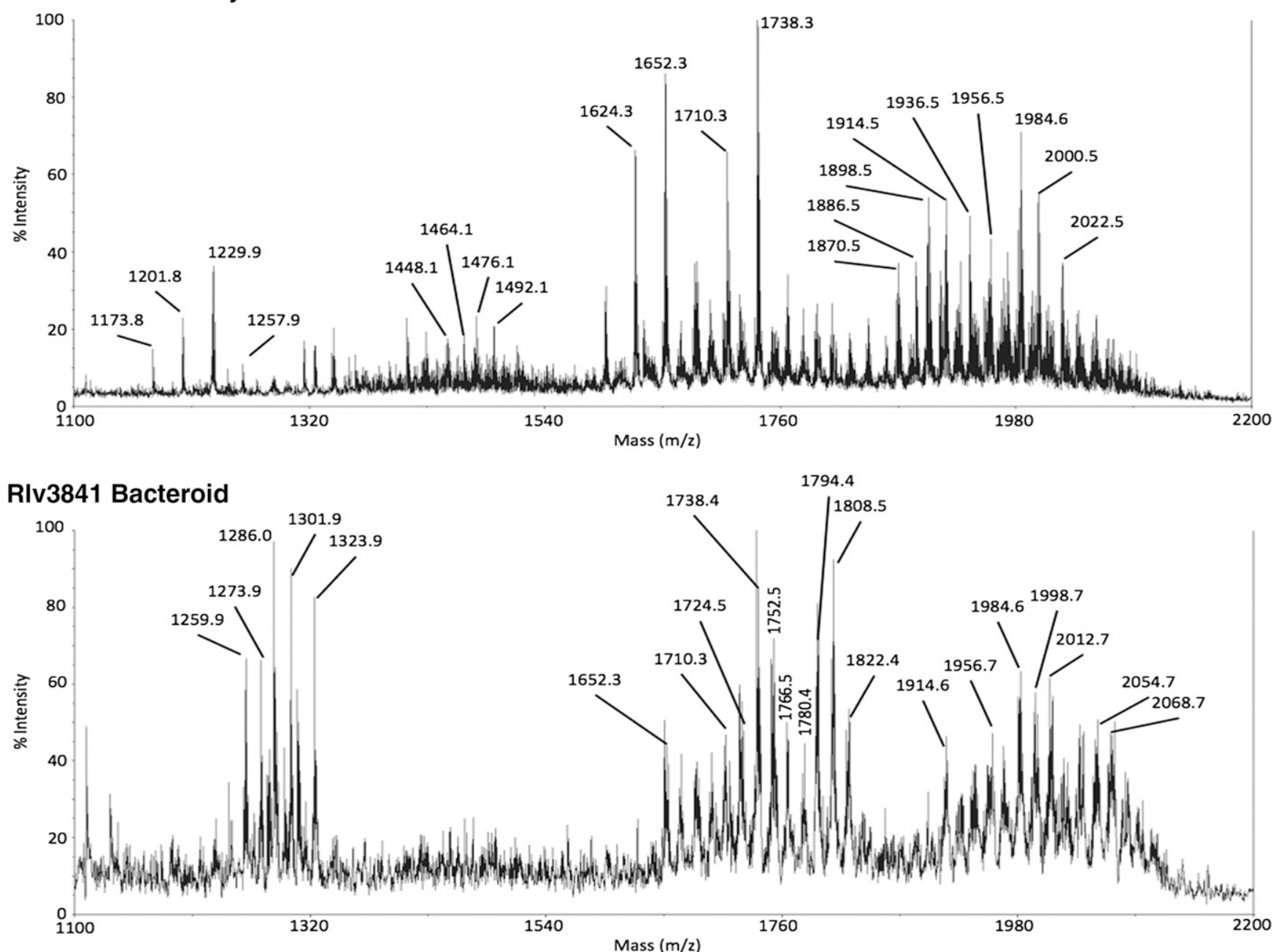

Fig. 4. Matrix-assisted laser desorption-ionization time of flight mass spectrum of the lipid A from strain Rlv3841 laboratory culture (top) and nodule bacteria or bacteroids (bottom). The $\mathrm{m} / \mathrm{z}$ mass ions of the bacteroid-derived lipid A spectrum, generally, have longer fatty acyl chains than in those observed for lipid A from Rlv3841 laboratory culture. Ions between 1173.3 and $1323.9 \mathrm{~m} / \mathrm{z}$ represent Structure IV. Ions between 1448.1 and $1492.1 \mathrm{~m} / \mathrm{z}$ represent Structure III. Ions between 1624.3 and $1822.4 \mathrm{~m} / \mathrm{z}$ represent Structure II. Ions between 1870.5 and $1068.7 \mathrm{~m} / \mathrm{z}$ represent Structure IV. 
the levels of cyclic $\beta$-glucans for Rlv3841 and EL198 ExN isolates is currently unknown.

\section{Altered nitrogen fixation, nodule number, and bacteroid morphology.}

To explore the symbiotic phenotype and also to obtain ExN isolates for analysis, each strain was used to inoculate host pea plants. Each of the mutants was able to induce effective nodules

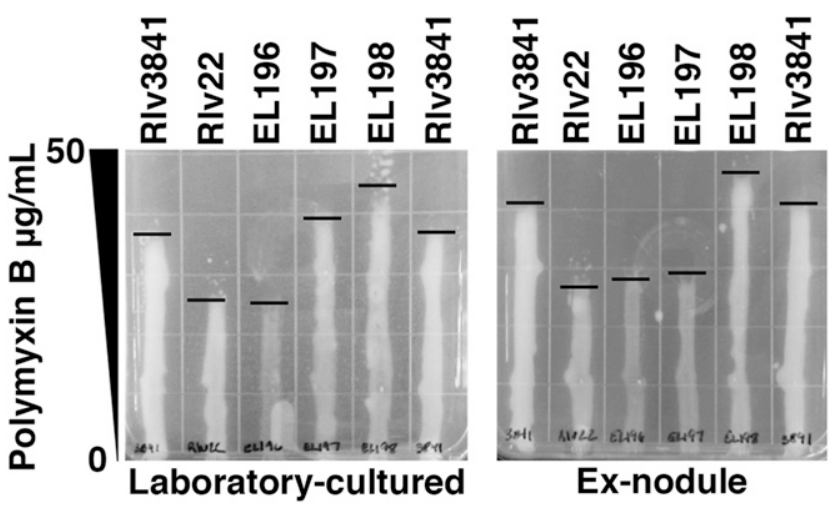

Fig. 5. Growth of laboratory-cultured and ex-nodule isolates of Rlv3841,

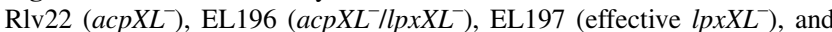
EL198 (double mutant fully complemented with pSSB1) isolates on tryptone-yeast extract gradient plates ranging from 0 to $50 \mu \mathrm{g} / \mathrm{ml}$ of polymyxin B. Solid black lines indicate the approximate distance of growth of each isolate.

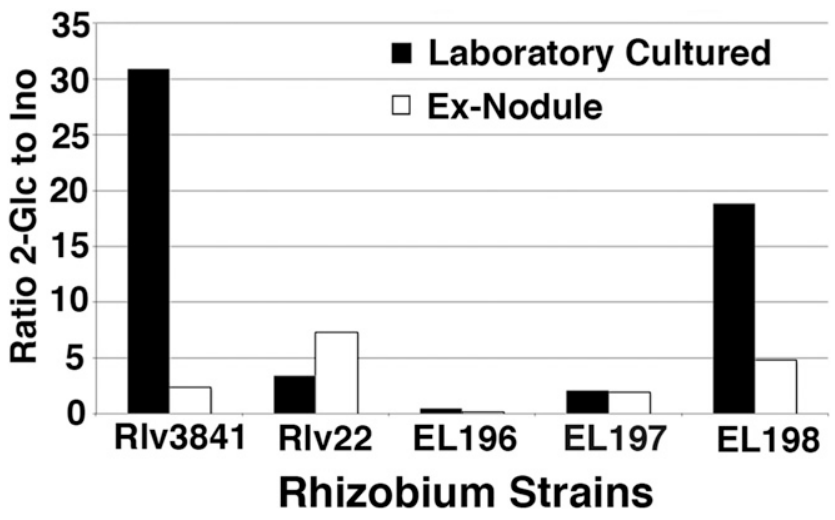

Fig. 6. Comparison of the levels of 2-linked glucose (2-Glc) measured by partially methylated alditol acetate analysis. Rlv3841, Rlv22 (acpXL $L^{-}$, EL196 (acpXL/lpxXL $L^{-}$), EL197 (effective lpxXL-), and EL198 (complemented double mutant) from laboratory-cultured (black bars) and exnodule (white bars) isolates were measured. on pea plants and formed pink root nodules. Variability was observed between one or more of the acpXL and $l p x X L$ mutant phenotypes with regard to the efficiency of the interaction (i.e., nitrogen fixation), onset of nodulation, nodule number and average nodule size, nodule internal organization, and bacteroid properties such as shape, occupation density, and size.

Nitrogen fixation was measured by exposing the plant root system from different days postinfection (dpi) to acetylene and measuring the percentage of ethylene evolved (Table 4). At 14 dpi, pea root nodules induced by parent strain Rlv3841 produced a significantly higher percentage of ethylene as compared with EL196 (acpXL $\left.L^{-} / l p x X L^{-}\right)$nodules and EL197 (lpxXL $\left.L^{-}\right)$nodules. Rlv22 (acpXL $\left.L^{-}\right)$and strain EL198 (complemented double mutant) had intermediate percentages of ethylene production that were not significantly different from nodules from Rlv3841. At $21 \mathrm{dpi}$, a similar trend was seen. The highest percentage of ethylene production was observed for Rlv3841 nodules; it was significantly higher than EL196 and EL197. The nodules induced by Rlv22 and EL198 had, again, intermediate levels of acetylene production but were not significantly different than Rlv3841 nodules. At 28 dpi, host plants and nodules induced by strain Rlv3841 and the fully complemented EL198 strain were developmentally ahead of the plants from mutant-induced nodules to the extent that they exhausted their medium humidity and dried out, preventing another reading to be taken for these strains. At this time point, the nodules of Rlv22 had a significantly higher percentage of acetylene production than either EL196 or EL197. Thus, at all time points, plants infected with mutant strains impaired in LPS lipid A biosynthesis were less effective in nitrogen fixation compared with plants infected with the parent wild-type strain.

The ability of legume hosts to autoregulate nodule number has been shown to lead to an increased number of nodule initiations when individual nodules are not fully functional (Vasse et al. 1993). Since the $a c p X L$ and $l p x X L$ mutations both lead to impaired VLCFA insertion into lipid A and, presumably, to impaired nitrogen-fixation efficiency (discussed above), we checked whether pea plants infected with these mutants are also affected in nodule number and size (Table 5). The state of nodule development was scored visually as immature (small, white) or mature (large, pink). We found that a common feature of host plants that were infected with mutants impaired in lipid A VLCFA biosynthesis was a delay in the formation of mature nodules and a tendency to have more small nodules. At $14 \mathrm{dpi}$, plants infected with parent and mutant strains had more immature than mature nodules but the number of nodules did not significantly differ between strains. At 21 dpi, plants infected with EL196 had significantly more immature nodules than those infected with any other strain. EL198 had the most mature nodules, Rlv3841 and Rlv22 had an intermediate number, and EL196 and EL197 had the fewest mature nodules at 21 dpi.

Table 4. Ethylene production (as percentage of used acetylene volume) of nodule pea root systems induced by Rhizobium leguminosarum strains

\begin{tabular}{|c|c|c|c|c|c|}
\hline \multirow[b]{2}{*}{ Strain } & \multicolumn{5}{|c|}{ Percentage of ethylene } \\
\hline & 14 dpi $(n)^{y}$ & \% Wild type (WT) & 21 dpi $(n)$ & $\% \mathrm{WT}$ & 28 dpi $(n)$ \\
\hline Rlv3841 & $9.93 \pm 2.12 \mathrm{a}(7)$ & 100 & $5.81 \pm 2.04 \mathrm{a}(10)$ & 100 & $\mathrm{ND}^{\mathrm{z}}$ \\
\hline Rlv22 & $7.24 \pm 3.26$ a (6) & 72.9 & $4.66 \pm 2.26$ a (14) & 80.2 & $12.32 \pm 0.90 \mathrm{a}(5)$ \\
\hline EL196 & $4.63 \pm 0.86 b(6)$ & 46.6 & $2.73 \pm 1.24 \mathrm{~b}(23)$ & 47.0 & $9.67 \pm 1.49 \mathrm{~b}(5)$ \\
\hline EL197 & $2.85 \pm 0.68 b(6)$ & 28.7 & $3.28 \pm 1.47 \mathrm{~b}(20)$ & 56.5 & $7.96 \pm 1.79 \mathrm{~b}(5)$ \\
\hline EL198 & $7.64 \pm 1.30 \mathrm{a}(5)$ & 76.9 & $4.55 \pm 1.84 \mathrm{a}(22)$ & 78.3 & ND \\
\hline
\end{tabular}

$y$ Percentages are calculated from the ratio of the area under the peak for acetylene to the area under the peak for ethylene. $n$ is the number of plant root system analyzed for acetylene reduction. Values shown \pm standard deviation. Different letters indicate significance differences in percentage ethylene when compared with the parent strain Rlv3841 at 14 and 21 dpi $(P<0.05)$. At 28 dpi, differing superscripts within the column indicate significance differences in percentage ethylene between strains $(P<0.05)$.

$\mathrm{z} \mathrm{ND}=$ not determined. 
Overall, plants infected with double mutant EL196 had significantly more total nodules than those infected with Rlv3841, Rlv22, or EL198, while EL197 had an intermediate total nodule number.

We also investigated nodule tissue organization and bacteroid morphology of the mutants. While nodules of Rlv3841, Rlv22, and EL198 at 21 dpi had largely comparable nodule organization (not taking into account smaller developmental stage differences of the various nodules investigated), the nodules induced by EL196 and EL197 showed differences with diminished numbers of infected plant nodule cells and aberrations in nodule cell organization. Infected nodule cells were more loosely spaced and most of the cells lacked a visible vacuole (Supplementary Fig S6). Bacteroid shape was also affected. Examples of bacteroids from 14, 21, and 28 dpi of

Table 5. Number of immature (small, white) and mature (large, pink) nodules for Rlv3841, Rlv22, EL196, EL197, and EL198 at 14 and 21 days postinfection (dpi)

\begin{tabular}{lrcrr}
\hline Strain & $\boldsymbol{n}$ & Immature $^{\mathbf{z}}$ & Mature & Total $^{\mathbf{z}}$ \\
\hline 14 dpi & & & & \\
Rlv3841 & 7 & 122 & 25 & 147 \\
Rlv22 & 6 & 93 & 22 & 114 \\
EL196 & 6 & 99 & 12 & 111 \\
EL197 & 6 & 90 & 0 & 90 \\
EL198 & 5 & 92 & 14 & 105 \\
21 dpi & & & & \\
Rlv3841 & 14 & $63 \mathrm{~b}$ & 43 & $106 \mathrm{~b}$ \\
Rlv22 & 15 & $151 \mathrm{~b}$ & 44 & $114 \mathrm{~b}$ \\
EL196 & 13 & $91 \mathrm{~b}$ & 26 & $178 \mathrm{a}$ \\
EL197 & 12 & $32 \mathrm{~b}$ & 30 & $121 \mathrm{~b}$ \\
EL198 & 14 & 54 & $85 \mathrm{~b}$ \\
\hline
\end{tabular}

${ }^{\mathrm{y}} n$ is the number of plant root systems analyzed.

${ }^{\mathrm{z}}$ Different letters indicate significance differences in the number of nodules when compared with the parent strain Rlv3841 $(P<0.05)$. strains Rlv3841, Rlv22, EL196, EL197, and EL198 are shown in Figure 7. Strains Rlv3841 and EL198 both formed mostly normally shaped elongated Y-structure bacteroids, while Rlv22, EL196, and EL197 formed abnormally shaped bacteroids with increased branching, and nodule cells containing symbiosomes with multiple bacteroids (Figure 7 shows an example in the 28dpi panel). Some bacteroids of Rlv22, EL196, and EL197 also showed regions of dark spots or granules, which have been suggested to be a sign of bacteroid senescence (Fig. 8) (Melino et al. 2012). Comparable structures have not been discovered in respective nodules induced by the wild-type parent Rlv3841 strain or the complemented mutant EL198.

\section{DISCUSSION}

To thrive in soil and plant environments, rhizobia must be able to adapt to the stressors in these environments (Vriezen et al. 2007), e.g., low water activity and antimicrobial compounds, and results of this and other work support that bacterial LPS plays an important role in providing tolerance to these stressors. It is likely to be of importance for both survival within the rhizosphere and the establishment of symbiosis with host plants (Araujo et al. 1994; Fraysse et al. 2003). In particular, lipid A with its VLCFA is expected to be crucial for rhizobial survival in both soil and host-plant environments, as it anchors the LPS to the outer membrane of the rhizobial cell envelope.

\section{R. leguminosarum LPS and lipid A are environment-dependently modified.}

Overall, the relative fatty acid composition comparison of the lipid A from laboratory culture, nodule bacteria and bacteroids, and $\mathrm{ExN}$ bacteria suggests three adjustments in the lipid A fatty acid composition from free-living bacteria to nodule bacteria and bacteroids: i) a shift toward higher molecular weight LPS in all cases but particularly in mutants defective in acpXL,
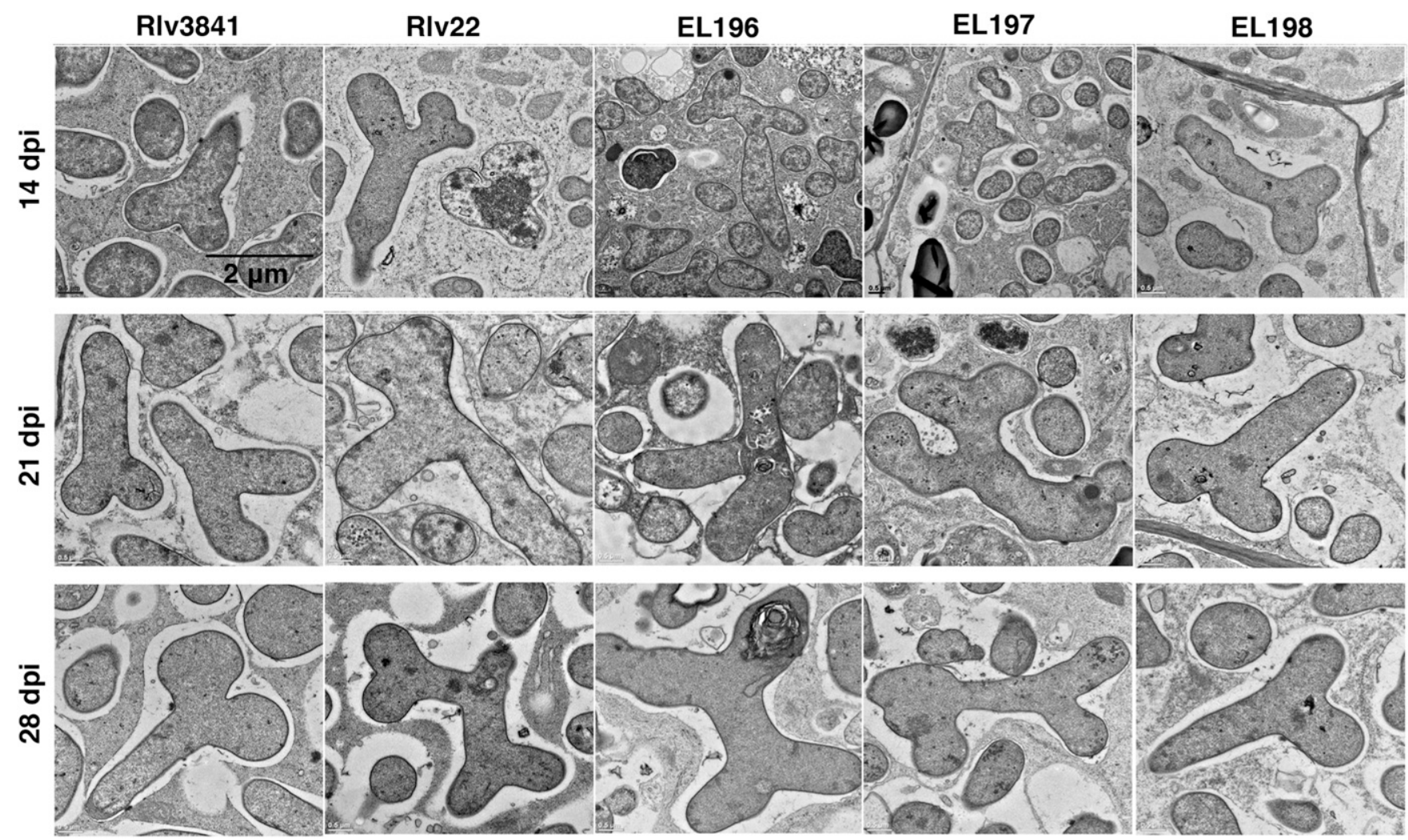

Fig. 7. Transmission electron microscopy images of individual Rlv3841, Rlv22, EL196, EL197, and EL198 bacteroids. Scale bar $=2 \mu \mathrm{m}$. 
indicating that bacteroid LPS from all strains contained higher molecular weight OPS than the LPS of laboratory-grown cultures; ii) an increase in the percentage of C16:0 and C18:0 fatty acids; iii) a decrease in the percentage of $3 \mathrm{OH}$ fatty acids (in particular that of $3 \mathrm{OHC14:0)}$; and iv) a pronounced increase in the relative percentage of $27 \mathrm{OHC} 28: 0$ in the LPS from the Rlv3841 parental strain (Table 1). These effects on lipid A composition could be the result of conditional LPS structure modification in nodule bacteria and bacteroids or the result of nodule selection pressure favoring the growth of bacterial variants with modified lipid A composition. If, in fact, the latter would be the case, one could expect the lipid A fatty acid adjustments observed during nodule development would be permanent and also would be found in the derived laboratorycultured ExN isolates, but that was not the case. Taken together, the observed LPS and lipid A structural modifications indicate that genetic selection is not taking place but that a conditional tailoring of LPS and lipid A structure is occurring in the bacteria due to nodule conditions.

With regard to the mutants, the acpXL mutant was able, in part, to replace the VLCFA with C16:0 or C18:0; however, none of the lpxXL mutants were able to do this. Similar results were also observed for AcpXL and LpxXL from Sinorhizobium meliloti (Ferguson et al. 2005; Haag et al. 2011), corroborating for this bacterium that $\mathrm{LpxXL}$ is required for the transfer of the VLCFA as well as the C16:0 or C18:0 to the lipid A to form a pentaacylated lipid A (Ferguson et al. 2005).

It has been previously reported that the acpXL mutants of $R$. leguminosarum and $S$. meliloti are able to partially restore the addition of VLCFA while in plant nodules (Haag et al. 2009; Vedam et al. 2006). This restoration of the lipid A VLCFA in the nodule environment was not observed in this work and awaits further investigation. The VLCFA was detected, however, in lipid A preparations from EL197 bacteroids; but MALDI analysis of the lipid A from EL197 did not show any detectable lipid A species containing the VLCFA. A likely explanation for the VLCFA in the EL197 lipid A preparations could be that it was present as the VLCFA AcpXL conjugate that was not further processed because of the nonfunctional acyltransferase. This VLCFA AcpXL may have been present in high levels due to the extra copies of acpXL in EL197 and isolated with lipid A.

\section{Stress resistance of $R$. leguminosarum acpXL and $\operatorname{lpx} X \mathrm{XL}^{-}$mutants.}

A precondition for rhizobial survival in both soil and plant environments is the ability of the bacteria to adapt to local stressors, such as changes in osmolarity, humidity, and plant defense responses (e.g., antimicrobial peptides) (Brewin 1991; Erbs and Newman 2012; Kannenberg and Brewin 1989; Van de Velde et al. 2010). Each of the mutants, Rlv22 (acpXL ${ }^{-}$), EL196 (acpXL $L^{-} / l p x X L^{-}$), and EL197 (effective $l p x X L^{-}$), was affected in at least some of their stress-related properties, i.e., compared with the parental strain, they became slower growing (Supplementary
Fig. S7), sensitive to sodium chloride, detergents (SDS or DOC) (Table 3), the antimicrobial peptide PmxB (Fig. 5), or desiccation (Supplementary Fig. S8), and had lower levels of osmoprotective cyclic glucans (Fig. 6). These findings emphasize the importance of lipid A and the VLCFA for rhizobial stress adaptation and corroborate previous work that showed sensitivity to high osmolarity, detergents, and desiccation in other laboratory-cultured VLCFA mutants (Brown et al. 2011; Vanderlinde et al. 2010; Vedam et al. 2003). Slow growth and susceptibility to salt, detergents, desiccation, and a diminished amount of cyclic $\beta$-glucans are expected to be due to a loss of membrane stability caused by the lack of a VLCFA on the lipid A.

In this and previous work, it has been demonstrated that, after symbiotic passage through pea plants, the ExN isolates of acpXL and lpxXL mutants of $R$. leguminosarum and $S$. meliloti have restored tolerance to detergents and salt (Brown et al. 2011; Sharypova et al. 2003; Vedam et al. 2006). The mechanism for this restoration is still elusive. Vanderlinde and Yost (2012), studying detergent tolerance in the same $R$. leguminosarum strain, hypothesized that an inherited and not an adaptive mechanism restores detergent tolerance during the host-plant passage. Examination of our mutants showed that none of the ExN isolates from our set of mutants had lost the genetic mutation; a result that pointed toward an adaptive mechanism underlying our observations. To further examine possible mechanisms for restoration of detergent and osmotic tolerance, we investigated a known osmoprotectant in $R$. leguminosarum, the cyclic $\beta$-glucans from the parent strain, and mutant laboratory-cultured and ExN isolates. Compared with the parent strain, the amount measured of 2-Glc was low for the laboratory-cultured mutants that lack VLCFA and remained low for all strains, following passage through the plant. Thus, the amount of 2-Glc did correlate with the restoration of osmotic tolerance seen in the mutant ExN isolates. Therefore, the restoration to parental tolerance levels of stressors was not due to isolation of ExN isolates with increased levels of cyclic $\beta$-glucans. The mechanism for restoration of osmotic and detergent tolerance in mutant $\mathrm{ExN}$ isolates remains unknown.

\section{Nodule development of $R$. leguminosarum acpXL and $l p x X L^{-}$mutants.}

The lack of the VLCFA still allowed for effective pea nodules to develop, but nodule development was altered. Host plants that were infected with mutants that lack VLCFA were slower to form mature nodules, tended to have more small, often white nodules and had irregular infected-nodule cell organization, and symbiosomes containing multiple aberrantly shaped bacteroids that prematurely senesce. Since LPS has been suggested to be of importance in the later stages of nodule development (Kannenberg et al. 1998, Scheidle et al. 2005), it is tempting to speculate that the plant phenotypes observed in this report could be due to the defective LPS lipid As, which may lead primarily to destabilization of the bacterial membrane and,

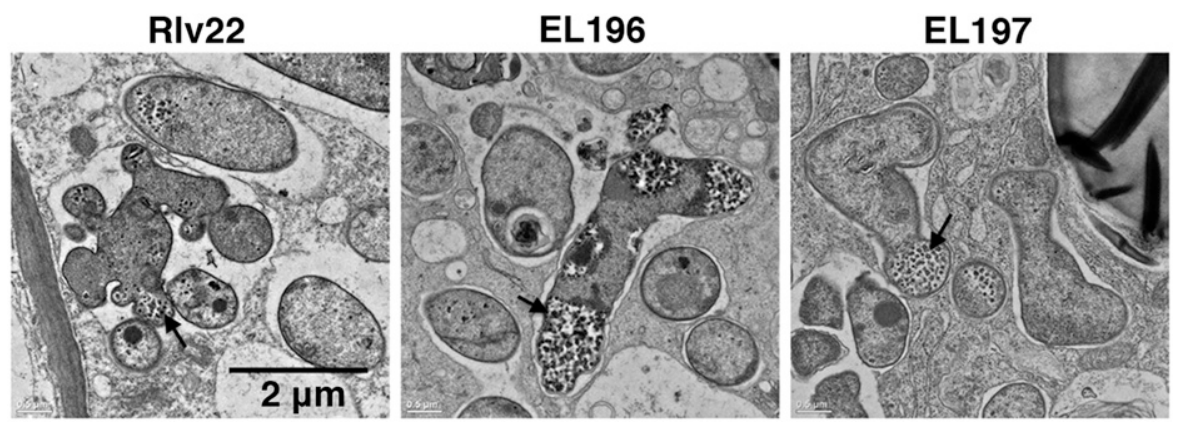

Fig. 8. Transmission electron microscopy images of individual mature bacteroids exhibiting degradation. Arrows are pointing to areas of degradation. 
also, possibly to some recognition by the host, causing a plant defense reaction and delayed nodule development. The sensitivity we found in some mutants that lack VLCFA toward the antimicrobial peptide $\mathrm{PmxB}$ seems to point in this direction. In addition to destabilization of the membrane, a defective interaction between nodule-specific cysteine-rich (NCR) peptides and the bacterial membrane of the mutants that lack VLCFA may be another mechanism leading to the alteration of nodule development, irregular nodule cell organization, and aberrantly shaped bacteroids. NCR peptides are produced in indeterminate nodules, are required for the prevention of bacterial cell division, and are necessary in forming an effective symbiosis (Mergaert et al. 2003; Van de Velde et al. 2010). The interaction of these mutants, as well as their LPSs, with these different classes of peptides that act upon bacterial LPS is a further area of research that should be explored.

Overall, the mutants have complex phenotypes and the mutant lipid As seem to have an impact on rhizobial uptake by nodule cells, on the interaction of the peribacteroid membrane and the bacterial surface necessary for bacteroid and symbiosome development. Bacteroid stability and, possibly, nutrient uptake may be leading to a delay in symbiotic developments or to premature senescence or both. Thus, the results of this report confirm and strongly support the importance of a pentaacylated lipid A with attached VLCFA for the stability and functioning of the outer membrane of the R. leguminosarum cell envelope in both symbiotic as well as soil environments. Many open questions about the functional details, however, remain unanswered, and much needs to be learned about the role of the VLCFA in rhizobial cell-envelope stability and stress adaptation.

\section{MATERIALS AND METHODS}

\section{Bacterial strains and growth conditions.}

Bacteria and plasmids used in this study are listed in Table 6. Escherichia coli strains were grown on Luria-Bertani (LB) medium at $37^{\circ} \mathrm{C}$ with appropriate antibiotics (Vedam et al. 2003). R. leguminosarum strains were grown at $30^{\circ} \mathrm{C}$ on tryptone-yeast extract (TY) medium with added calcium (Noel et al. 1986) and appropriate antibiotics. Antibiotics were used at the following concentrations $(\mu \mathrm{g} / \mathrm{ml})$ : tetracycline, 10 ; kanamycin,
50; gentamicin, 25; streptomycin, 200; and ampicillin, 50. For $\beta$-galactosidase blue and white colony screening, $100 \mu \mathrm{l}$ of $40 \mathrm{mM}$ isopropylthiogalactopyranoside (IPTG) and $100 \mu \mathrm{l}$ of $2 \%$ 5-bromo-4-chloro-3-indolyl- $\beta$-D-galactopyranoside (X-Gal) were spread onto each plate.

\section{Plant growth and inoculation conditions.}

For germination, 'Early Alaska' pea seeds were rinsed with $70 \%$ ethanol for $30 \mathrm{~s}$, were washed $3 \times$ with sterile distilled (d) $\mathrm{H}_{2} \mathrm{O}$, surface sterilized with $6 \%$ sodium hypochlorite for $1 \mathrm{~min}$, and were washed $10 \times$ with sterile $\mathrm{dH}_{2} \mathrm{O}$. The sterilized seeds were transferred to $300 \mathrm{ml}$ of nitrogen-free Fahraeus medium (Nutman 1970) in 500-ml foam stoppered flasks and were allowed to germinate for 10 to 13 days at $22^{\circ} \mathrm{C}$ for $14 \mathrm{~h}$ of light, followed by $10 \mathrm{~h}$ of darkness at $18^{\circ} \mathrm{C}$, and ambient relative humidity. Following germination, stems were manipulated out of the top of the flask and the foam stopper was gently reinserted, allowing the stem and leaves of the plant to grow outside the flask. Each plant was inoculated with $1 \mathrm{ml}$ of an approximately 0.15 optical density at $600 \mathrm{~nm}\left(\mathrm{OD}_{600}\right) \log$ phase culture (approximately $10^{8} \mathrm{CFU} / \mathrm{ml}$ ) by dripping onto the seed and emerged roots. Each flask was then covered with a brown paper bag and was taped closed, to minimize light exposure to the roots while leaving the foam stopper and stem and leaves of the plant exposed to light. The pea plants were allowed to grow each day as described above for up to $28 \mathrm{dpi}$.

\section{Bacteroid isolation.}

For chemical analysis, plant nodules with bacteroids were collected at $21 \mathrm{dpi}$. Nodules from approximately 50 plants per strain were removed from the roots with forceps and were collected in a $0.5 \mathrm{M}$ sucrose buffer $(50 \mathrm{mM}$ Tris, $10 \mathrm{mM}$ dithiothreitol [DTT], 0.5 M sucrose, $\mathrm{pH}$ 7.4).

Subsequent to their harvest, the nodules were removed from the buffer and were ground with a mortar and pestle in a small amount of a freshly prepared buffer with $0.5 \mathrm{M}$ sucrose $5 \%$ (wt/vol) polyvinylpolypyrrolidone and $(5 \mathrm{mM})$ p-aminobenzamidine. The slurry of plant material and nodule bacteria (i.e., predominantly bacteroids) was filtered through a syringe packed with $1 \mathrm{~cm}$ of glass wool. The bacteroids from the filtrate were further isolated by sucrose gradient ultracentrifugation. The sucrose gradients consisted

Table 6. Bacterial strains and plasmids used in this study

\begin{tabular}{|c|c|c|}
\hline Strain/plasmid & Characteristics $^{\mathbf{z}}$ & Source \\
\hline \multicolumn{3}{|l|}{ Escherichia coli } \\
\hline XL1 Blue & $\begin{array}{l}\text { endA } 1, \text { recA1, gyrA96, thi, hsdR17 }\left(\mathrm{rk}^{-}, \mathrm{mk}^{+}\right) \text {, relA1, supE44, lac, }\left(\mathrm{F}^{\prime}, \text { proAB }\right. \\
\left.\text { laclqZ } \Delta \mathrm{M} 15,:: \mathrm{T} n 10\left[\mathrm{Tet}^{+}\right]\right)\end{array}$ & Stratagene Corp. \\
\hline DH5 $\alpha$ & $\begin{array}{l}\Phi 80 \mathrm{~d} l a c Z \Delta \mathrm{M} 15, \text { recA1, endA1, gyrA96, thi-1, hsdR17 }\left(\mathrm{rk}^{-}, \mathrm{mk}^{+}\right), \text {supE } 44, \\
\quad \text { relA1, deoR, } \Delta(\text { lacZYAargF }) \mathrm{U} 169\end{array}$ & Stratagene Corp. \\
\hline \multicolumn{3}{|c|}{ Rhizobium leguminosarum bv. viciae } \\
\hline Rlv3841 & Strain 300 Str $^{r}$, Fix ${ }^{+}$ & Wang et al. 1982 \\
\hline Rlv22 & Strain 3841 acpXL:: km $\mathrm{Str}^{\mathrm{r}}, \mathrm{Kan}^{\mathrm{r}}, \mathrm{Fix}^{+}$ & Vedam et al. 2003 \\
\hline EL196 & Strain Rlv22 lpxXL::gm $\mathrm{Str}^{\mathrm{r}}, \mathrm{Kan}^{\mathrm{r}}, \mathrm{Gen}^{\mathrm{r}}, \mathrm{Fix}^{+}$ & This study \\
\hline EL197 & Strain EL196 pVV5 with acpXL, Str ${ }^{\mathrm{r}}, \mathrm{Kan}^{\mathrm{r}}, \mathrm{Gen}^{\mathrm{r}}, \mathrm{Tet}^{\mathrm{r}}, \mathrm{Fix}^{+}$ & This study, Vedam et al. 2003 \\
\hline EL198 & Strain EL196 pSSB-1 with $a c p X L, l p x X L$, Str $^{\mathrm{r}}, \mathrm{Kan}^{\mathrm{r}}, \mathrm{Gen}^{\mathrm{r}}, \mathrm{Tet}^{\mathrm{r}}, \mathrm{Fix}^{+}$ & This study, Basu et al. 2002 \\
\hline \multicolumn{3}{|c|}{${ }^{2}$} \\
\hline pSSB-1 & $\begin{array}{l}\text { pLAFR-1 with 22-kb Rhizobium leguminosarum genomic DNA (RL2810 to } \\
\text { RL2832) }\end{array}$ & Basu et al. 2002 \\
\hline pBS II SK+ & 2.96-kb phagemid derived from pUC19, lacZ, $\mathrm{Amp}^{\mathrm{r}}$ & Stratagene Corp. \\
\hline pVV5 & pVV1 derivative cloned into pBBR1MCS-3 containing acpXL & Vedam et al. 2003 \\
\hline pDVB1 & pBS SK derivative with $2.6-\mathrm{kb}$ insert from pSSB-1 containing $l p x X L$ & This study \\
\hline pDVB2 & pDVB1 containing aac $C 1$ cassette from pMS255 & This study \\
\hline pDVB3 & pDVB2 derivative cloned into $\mathrm{pEx} 18 \mathrm{Tc}$ & This study \\
\hline pMS255 & Gen $^{\mathrm{r}}$ cassette in pSVB30 & Becker et al. 1995 \\
\hline pEX18Tc & Broad-host range suicide vector, Tet $^{\mathrm{r}} s a c B^{+}$ & Hoang et al. 1998 \\
\hline pRK600 & Mobilizing plasmid & Finan et al. 1986 \\
\hline pRK2013 & Mobilizing plasmid & Ditta et al. 1980 \\
\hline
\end{tabular}

${ }^{\mathrm{z}} \mathrm{Tet}^{\mathrm{r}}, \mathrm{Str}^{\mathrm{r}}, \mathrm{Kan}^{\mathrm{r}}, \mathrm{Gen}^{\mathrm{r}}$, and $\mathrm{Amp}^{\mathrm{r}}=$ resistance to tetracycline, streptomycin, kanamycin, gentamycin, and ampicillin. 
of $2 \mathrm{ml}$ of each of the following: $70,52,35,25$, and 17.5 sucrose in Tris buffer (50 mM Tris, $10 \mathrm{mM}$ DTT, $\mathrm{pH} 7.4)$. The bacteroid filtrate was layered on top of the sucrose gradient and was ultracentrifuged at $100,000 \times g$ for $4 \mathrm{~h}$. The bacteroid layer, a dark pink section between the 70 and $52 \%$ sucrose layers, was removed from the gradient, was diluted in $30 \mathrm{ml}$ of buffer $(50 \mathrm{mM}$ Tris, $10 \mathrm{mM}$ DTT, $\mathrm{pH}$ 7.4), and was centrifuged at $4,000 \times g$ for $30 \mathrm{~min}$. The pellet was resuspended in extraction buffer $\left(0.05 \mathrm{M} \mathrm{Na}_{2} \mathrm{PO}_{4} \cdot 7 \mathrm{H}_{2} \mathrm{O}\right.$, $0.005 \mathrm{M}$ EDTA, $0.05 \%$ [wt/vol] $\mathrm{NaN}_{3}, \mathrm{pH} 7$ ), and was stored at $-20^{\circ} \mathrm{C}$.

\section{ExN bacterial isolation.}

To allow for comparison of strain properties before and after passage through the nodules, for each mutant, isolates were obtained from mature, fully developed root nodules. This isolate is referred to as the ExN isolate. Several nodules were picked from a root system and each nodule was individually washed and surface sterilized with $6 \%$ sodium hypochlorite for approximately $30 \mathrm{~s}$ and was then washed four times with sterile $\mathrm{dH}_{2} \mathrm{O}$. The individual nodules were crushed with a pair of sterile forceps onto a TY plate with the appropriate antibiotics and were streaked with a sterile loop for individual colonies. The resulting colonies were restreaked for purity and were stored in glycerol stocks. Each ExN isolate was confirmed through correct antibiotic resistance and retaining the antibiotic resistance cassettes within the correct gene through PCR.

\section{Mutant construction.}

Plasmid pSSB-1, containing the R. leguminosarum chromosomal gene region with the cluster of genes required for VLCFA biosynthesis and attachment to the lipid A (Basu et al. 2002), was used for isolation of the lpxXL gene RL2812. For that, the plasmid was digested with restriction enzyme PstI, creating a 2.6-kb fragment harboring $l p x X L$ with flanking regions stretching 1,271 bp upstream (including the alcohol dehydrogenase RL2813 and a small fragment of $f a b F 1 X L$ ) and 423-bp region downstream of lpxXL (encoding a small fragment of RL2811, a hypothetical protein). This fragment containing $l p x X L$ was cloned into pBluescript $\mathrm{pBSII} \mathrm{SK}^{+}$creating $\mathrm{pDVB} 1$. The $\mathrm{pDVB} 1$ plasmid was used to transform E. coli XL1-B cells and was grown on LB plates with ampicillin, X-Gal, and IPTG. White colonies were selected and restreaked, and the derived plasmid preparations were restrictiondigested and viewed on an agarose gel to confirm the presence of the construct.

For $l p x X L$ gene interruption, the gentamicin-resistance cassette aacC1 (Becker et al. 1995) was inserted into lpxXL. For that, plasmid pDVB1 was restriction-digested with AccIII and aacCl-containing plasmid pMS255 with XmaI and the fragments were ligated to form pDVB2. E. coli DH5 $\alpha$ was transformed with $\mathrm{pDVB} 2$ and was selected for growth on LB plates with gentamicin. Transformants were restreaked and the constructs were confirmed through restriction digestion and gel electrophoresis of the isolated plasmid. Both forward and reverse orientations of the gentamicin cassette were obtained and an orientation opposite to the $l p x X L$ gene orientation was used.

For $\operatorname{lp} x X L$ inactivation, $\operatorname{lp} x X L$ carrying the aacC1 insertion was cloned into the broad host range suicide vector $\mathrm{pEX} 18 \mathrm{Tc}$ (Hoang et al. 1998). The pDVB2 fragment containing lpxXL::gm was Sac1-digested, gel-extracted, and ligated with the EcoR1digested $\mathrm{pEx} 18 \mathrm{Tc}$ to form $\mathrm{pDVB} 3$, which was transformed into E. coli $\mathrm{DH} 5 \alpha$ and was selected for antibiotic resistance on LB plates with gentamicin and tetracycline. The correct transformants were confirmed by restriction digestion and gel electrophoresis.

Plasmid pDVB3 was introduced into $R$. leguminosarum bv. viciae 3841 and 22 through triparental mating with E. coli DH5 $\alpha, \mathrm{pDVB} 3$ as the donor, Rlv3841 or Rlv22 as the recipient, and E. coli pRK2013 (Ditta et al. 1980) as the helper. Single recombinants were selected on TY with gentamicin and streptomycin and were then replica-plated onto TY with gentamicin, streptomycin, and $10 \%$ sucrose for selection of double recombinants. Three double acpXL::km lpxXL::gm mutants were isolated (EL196, DM13, DM15). However, no lpxXL::gm single mutants could be constructed. Mutations were confirmed by PCR with primers for $l p x X L$ (AATGAGGGTGGACGTTCTTG and GTTCGACTACGATCCCGAAA) and $a c p X L$ (ATTGCAGAA ACCAGCGAGAT and AGAAACCTTGCCTTCGTTGA).

Because we failed to isolate a lpxXL::gm mutant, the acpXL:: $\mathrm{km}$, lpxXL::gm double mutant EL196 was partially complemented with the parental acpXL (cloned in plasmid pVV5) to create effective $R$. leguminosarum lpxXL mutant EL197, i.e., $a c p X L^{-} l p x X L^{-} a c p X L^{+}$. The pVV5 plasmid (Vedam et al. 2003) with the $a c p X L$ gene was introduced into EL196 through triparental mating of $E$. coli $\mathrm{pVV} 5$ donor strain, with $R$. leguminosarum EL196 as the recipient, and E. coli pRK600 as helper strain. Transformants were selected on TY with gentamicin, kanamycin, and tetracycline. Loss of complementing plasmid pVV5 in lab culture of EL197 and in planta was not observed. Full complementation of the $R$. leguminosarum EL196 mutant was accomplished by the triparental mating of E. coli pSSB1 as donor, R. leguminosarum EL196 as acceptor, and pRK2013 as helper creating $R$. leguminosarum strain EL198. Transformants were selected on TY agar with tetracycline and streptomycin and were confirmed with PCR.

\section{LPS extraction and purification.}

Each mutant and, in addition, a derived ExN isolate from each mutant obtained from the mutant-induced host root nodules (here termed ExN isolates) were grown at $30^{\circ} \mathrm{C}$ overnight in TY liquid media with added calcium (Noel et al. 1986) and appropriate antibiotics, were collected by centrifugation from 4-liter cultures (approximate $\mathrm{OD}_{600}=1.0$ ), were washed with $0.9 \% \mathrm{NaCl}$, and were washed $3 \times$ with sterile $\mathrm{dH}_{2} \mathrm{O}$, and the pellet was suspended in $20 \mathrm{ml}$ of sterile $\mathrm{dH}_{2} \mathrm{O}$. LPS was isolated by hot phenol-water extraction (Westphal and Jann 1965). Briefly, the cell pellet in $20 \mathrm{ml}$ of sterile $\mathrm{dH}_{2} \mathrm{O}$ and $20 \mathrm{ml}$ of hot phenol was heated at $65^{\circ} \mathrm{C}$ for $45 \mathrm{~min}$, was cooled for $5 \mathrm{~min}$ in ice water, was centrifuged (7,000 to $10,000 \mathrm{rpm}$ for $25 \mathrm{~min}$, using a JA-20 fixed-angle rotor) to separate the water and phenol layers, and the water layer was collected. Then, $18 \mathrm{ml}$ of $\mathrm{dH}_{2} \mathrm{O}$ was added to the phenol layer and the extraction procedure was repeated twice more, after which pooled water layers and the phenol layers were dialyzed (molecular weight cut-off $[\mathrm{MWCO}]=2,000$ ). Following dialysis against $\mathrm{dH}_{2} \mathrm{O}$, LPS was lyophilized and was further purified with RNase, DNase, and proteinase treatments.

For bacteroid LPS isolation, the bacteroid pellet was extracted by micro hot phenol-water extraction (Westphal and Jann 1965). Micro hot phenol-water extractions were completed as described for free-living and ExN bacteria, except volumes of $1 \mathrm{ml}$ were used instead of $20 \mathrm{ml}$. Water layer LPS was used for all analyses.

\section{LPS characterization.}

Isolated LPSs were separated on a DOC-PAGE gel and were visualized using Alcian blue/silver staining as described (Reuhs et al. 1993). One microgram of LPS in loading buffer was loaded into each well of the DOC-PAGE gel and was separated by gel electrophoresis.

To isolate the lipid A component of the LPS, $1 \mathrm{mg}$ of LPS was subjected to mild acid hydrolysis by incubation in $1 \mathrm{ml}$ of $1 \%$ acetic acid at $100^{\circ} \mathrm{C}$ for $2 \mathrm{~h}$. (Caroff et al. 1988). Following hydrolysis, the lipid A was isolated by an initial extraction with $2 \mathrm{ml}$ of $\mathrm{MeOH} /$ chloroform (1:1) and two subsequent extractions with $1 \mathrm{ml}$ of chloroform. The chloroform layers containing the lipid A were dried and weighed. 
Lipid A preparations were analyzed by GC-MS (combined gas chromatography and mass spectrometry) of trimethylsilyl glycosides and MALDI-TOF MS. Samples were analyzed in a 30-m DB-5 column following methanolysis in methanolic $1 \mathrm{M}$ $\mathrm{HCl}$ and trimethylsilylation (Ramadas Bhat et al. 1991; York et al. 1985). The lipid A was also analyzed by MALDI (MS) using an AB SCIEX TOF/TOF 5800 high-resolution mass spectrometer in the negative-ion reflective mode. Lipid A preparations were dissolved in 3:1 chloroform/methanol, and $2 \mu \mathrm{l}$ were mixed with $2 \mu \mathrm{l}$ of THAP $(2,4,6$ trihydroxyacetophenone monohydrate) and were spotted on a plate for mass analysis.

\section{Mutant sensitivity phenotype analysis.}

To assess osmotic tolerance of the bacterial strains, rhizobial cells were streaked onto TY plates containing $0.25,0.50$, and $0.75 \% \mathrm{NaCl}$. Sensitivity to detergents was determined by streaking strains on TY agar plates containing SDS at 0.17 , $0.35,0.52$, and $0.69 \mathrm{mM}$ or DOC at $0.51,0.64,0.76,1,2$, and $3 \mathrm{mM}$. Following 3 days of incubation at $30^{\circ} \mathrm{C}$, the relative amounts of growth were assessed visually and were assigned a + or - value. Resistance to PmxB was analyzed by streaking strains $\left(10 \mu \mathrm{l}\right.$ of a liquid culture at $\left.\mathrm{OD}_{600}=0.2\right)$ onto $\mathrm{TY}$ gradient plates containing 0 to $50 \mu \mathrm{g}$ of $\mathrm{PmxB}$ per milliliter.

\section{Cyclic $\beta$-glucan analysis.}

Cyclic $\beta$-glucans coextract with LPS during phenol-water extraction, thus, the relative amount of cyclic $\beta$-glucans can be estimated using a preparation of crude LPS. LPS for each mutant and the parent strain and their ExN isolates was extracted as described above from 1-liter cultures $\left(\mathrm{OD}_{600}\right.$ of approximately 1.0) and was dialyzed with $\mathrm{MWCO}=1,000$. The amount of total carbohydrate in the water layer was analyzed by a phenol sulfuric acid test. For each strain, $100 \mu \mathrm{g}$ of lyophilized material extracted into the water layer was diluted in $100 \mu \mathrm{l}$ of $\mathrm{dH}_{2} \mathrm{O}$. Then, $100 \mu \mathrm{l}$ of $5 \%$ phenol in water and $500 \mu \mathrm{l}$ of concentrated $\mathrm{H}_{2} \mathrm{SO}_{4}$ was added to each sample. Samples were heated at $99^{\circ} \mathrm{C}$ for $5 \mathrm{~min}$ and were then cooled to room temperature. Absorbance was measured at $460 \mathrm{~nm}$ and total carbohydrate for each sample was calculated, based on a glucose standard curve, from 5 to $60 \mu \mathrm{g}$ of glucose. Based on the results from the total carbohydrate analysis, the weight of lyophilized LPS equivalent to $200 \mu \mathrm{g}$ of carbohydrates was utilized for linkage analysis.

Linkage analysis of neutral sugars (particularly 2-Glc) was determined using the Ciucanu permethylation method (Ciucanu and Kerek 1984), and conversion to partially methylated alditol acetates was determined as described previously (Darvill et al. 1985). Analysis was performed using combined GC-MS. It is expected that the 2-Glc analyzed was present within the periplasm and was not secreted 2-Glc, due to washing of the cells removing secreted 2-Glc prior to LPS isolation. A known inositol standard was used for quantification of 2-Glc.

\section{Acetylene reduction assay.}

To assess nitrogen fixation, the amount of acetylene reduced to ethylene was determined. For each plant, the root system was removed at the seed coat and was placed inside a 100-ml glass bottle with a septum stopper. Acetylene gas $(1 \mathrm{ml})$ was injected into each bottle. After $1 \mathrm{~h}, 0.3 \mathrm{ml}$ of gas was removed from the bottle through the diaphragm and was injected into a gas chromatograph (isothermal at $70^{\circ} \mathrm{C}$, with a $25 \mathrm{~m}$ by $0.53 \mathrm{~mm}, 10 \mu \mathrm{m}$ $\mathrm{Al}_{2} \mathrm{O}_{3} / \mathrm{KCl}$ column). The ratio of ethylene to acetylene (area under the peak) was calculated for determination of acetylene reduction.

\section{Nodule preparation for microscopy.}

Plant roots were removed from Fahraeus medium and smaller sections of roots with nodules were harvested. Nodules to be used for confocal microscopy were placed into a $4 \%$ formaldehyde, $100 \mathrm{mM}$ PIPES fixative solution, and nodules to be used for transmission electron microscopy (TEM) were placed into a $4 \%$ formaldehyde, $1 \%$ glutaraldehyde, $100 \mathrm{mM}$ PIPES fixative solution. Under a stereo microscope, nodules were dissected longitudinally perpendicular to the outgrowth at the root, with a double-edged razor blade, while submerged in the fixative solution, and a section containing the middle of the nodule attached to the root was collected. Sections were transferred to $8 \mathrm{ml}$ of fixative in a scintillation vial and were fixed overnight at $4{ }^{\circ} \mathrm{C}$ with gentle agitation.

\section{TEM.}

Nodule sections fixed in $4 \%$ formaldehyde, $1 \%$ glutaraldehyde, and $100 \mathrm{mM}$ PIPES were rinsed $3 \times$ for $15 \mathrm{~min}$ with distilled water and were postfixed in $1 \%$ osmium tetroxide for $2 \mathrm{~h}$, with rotation. Postfixed samples were rinsed $3 \times$ for $15 \mathrm{~min}$ with distilled water with rotation. Samples were then dehydrated stepwise in solutions of acetone in water $(10,30,50$, 70,90 , and $100 \%$ with $100 \%$ repeated a second time) for $30 \mathrm{~min}$ each, while rotating at room temperature and were subsequently infiltrated stepwise with graded solutions of Epon Araldite $(25,50,75 \%$, in acetone and $100 \%$ with $100 \%$ repeated a second time) for $1 \mathrm{~h}$ each, with rotation at room temperature. The final 100\% Epon Araldite infiltration resin was held overnight, with rotation, at room temperature. The next day, the resin was replaced with fresh $100 \%$ Epon Araldite for infiltration with rotation, for $8 \mathrm{~h}$. Resin was, again, replaced with $100 \%$ Epon Araldite and was transferred with nodule sections into an aluminum weigh boat and was polymerized at $65^{\circ} \mathrm{C}$ for $72 \mathrm{~h}$. Embedded nodule samples were cut out and were mounted onto acrylic mounting stubs for trimming on a microtome. Once trimmed, 70-nm parallel sections were cut with a diamond knife and were collected onto gold hex mesh grids. Grids were submerged into $2 \%$ aqueous uranyl acetate (Catalano et al. 2004) for $15 \mathrm{~min}$ and were rinsed eight times with distilled water. Sections were stained with lead citrate for $10 \mathrm{~min}$ and were washed eight times with distilled water (Reynolds 1963). Once dry, grids with sections were carbon coated. Sections were imaged with a Zeiss Libra 120 TEM at $80 \mathrm{kV}$.

\section{Nodule and bacteroid measurements.}

Nodule size was determined from five to 15 pea plants per bacterial strain. All nodules on each plant root system were visually categorized as immature (small, white) or mature (large, pink). TEM images were analyzed with ImageJ. Statistical significance was determined using the GLM procedure of SAS. Mean separation was conducted by analysis of variance and Tukey's honestly significant difference test. Significance was determined at $P<0.05$.

\section{ACKNOWLEDGMENTS}

The authors thank C. Raetz for supplying the pSSB-1 plasmid and D. Mohnen for critical reading of the manuscript. This work was supported, in part, by National Institutes of Health grant GM39583 (to R. W. Carlson) and by the Department of Energy grant DE-FG-02-93ER20097 to the Complex Carbohydrate Research Center.

\section{LITERATURE CITED}

Araujo, R. S., Robleto, E. A., and Handelsman, J. 1994. A hydrophobic mutant of Rhizobium etli altered in nodulation competitiveness and growth in the rhizosphere. Appl. Environ. Microbiol. 60:1430-1436.

Ardissone, S., Kobayashi, H., Kambara, K., Rummel, C., Noel, K. D., Walker, G. C., Broughton, W. J., and Deakin, W. J. 2011. Role of BacA in lipopolysaccharide synthesis, peptide transport, and nodulation by Rhizobium sp. strain NGR234. J. Bacteriol. 193:2218-2228. 
Basu, S. S., Karbarz, M. J., and Raetz, C. R. 2002. Expression cloning and characterization of the $\mathrm{C} 28$ acyltransferase of lipid A biosynthesis in Rhizobium leguminosarum. J. Biol. Chem. 277:28959-28971.

Becker, A., Schmidt, M., Jäger, W., and Pühler, A. 1995. New gentamicinresistance and lacZ promoter-probe cassettes suitable for insertion mutagenesis and generation of transcriptional fusions. Gene 162: 37-39.

Breedveld, M. W., Zevehuizen, L. P. T. M., and Zehnder, A. J. B. 1990 Osmotically induced oligo- and polysaccharide synthesis by Rhizobium meliloti SU-47. J. Gen. Microbiol. 136:2511-2519.

Brewin, N. J. 1991. Development of the legume root nodule. Annu. Rev. Cell Biol. 7:191-226.

Brown, D. B., Huang, Y. C., Kannenberg, E. L., Sherrier, D. J., and Carlson, R. W. 2011. An acpXL mutant of Rhizobium leguminosarum bv. phaseoli lacks 27-hydroxyoctacosanoic acid in its lipid A and is developmentally delayed during symbiotic infection of the determinate nodulating host plant Phaseolus vulgaris. J. Bacteriol. 193:4766-4778.

Buch, A. D., Archana, G., and Naresh Kumar, G. 2010. Broad-host-range plasmid-mediated metabolic perturbations in Pseudomonas fluorescens 13525. Appl. Microbiol. Biotechnol. 88:209-218.

Caroff, M., Tacken, A., and Szabó, L. 1988. Detergent-accelerated hydrolysis of bacterial endotoxins and determination of the anomeric configuration of the glycosyl phosphate present in the "isolated lipid A" fragment of the Bordetella pertussis endotoxin. Carbohydr. Res. 175: 273-282.

Catalano, C. M., Lane, W. S., and Sherrier, D. J. 2004. Biochemical characterization of symbiosome membrane proteins from Medicago truncatula root nodules. Electrophoresis 25:519-531.

Ciucanu, L., and Kerek, F. 1984. A simple and rapid method for the permethylation of carbohydrates. Carbohydr. Res. 131:209-217.

Colonna-Romano, S., Arnold, W., Schlüter, A., Boistard, P., Pühler, A., and Priefer, U. B. 1990. An Fnr-like protein encoded in Rhizobium leguminosarum biovar viciae shows structural and functional homology to Rhizobium meliloti FixK. Mol. Gen. Genet. 223:138-147.

Corbel, M. J. 1997. Brucellosis: An overview. Emerg. Infect. Dis. 3:213-221.

D’Haeze, W., Leoff, C., Freshour, G., Noel, K. D., and Carlson, R. W. 2007. Rhizobium etli CE3 bacteroid lipopolysaccharides are structurally similar but not identical to those produced by cultured CE3 bacteria. J. Biol. Chem. 282:17101-17113.

Darvill, A. G., Albersheim, P., McNeil, M., Lau, J. M., York, W. S., Stevenson, T. T., Thomas, J., Doares, S., Gollin, D. J., Chelf, P., and Davis, K. 1985. Structure and function of plant cell wall polysaccharides. J. Cell Sci.Suppl. 1985:203-217.

Ditta, G., Stanfield, S., Corbin, D., and Helinski, D. R. 1980. Broad host range DNA cloning system for gram-negative bacteria: Construction of a gene bank of Rhizobium meliloti. Proc. Natl. Acad. Sci. U.S.A. 77:7347-7351.

Erbs, G., and Newman, M. A. 2012. The role of lipopolysaccharide and peptidoglycan, two glycosylated bacterial microbe-associated molecular patterns (MAMPs), in plant innate immunity. Mol. Plant Pathol. 13:95-104.

Ferguson, G. P., Datta, A., Carlson, R. W., and Walker, G. C. 2005. Importance of unusually modified lipid A in Sinorhizobium stress resistance and legume symbiosis. Mol. Microbiol. 56:68-80.

Finan, T. M., Kunkel, B., De Vos, G. F., and Signer, E. R. 1986. Second symbiotic megaplasmid in Rhizobium meliloti carrying exopolysaccharide and thiamine synthesis genes. J. Bacteriol. 167:66-72.

Fraysse, N., Couderc, F., and Poinsot, V. 2003. Surface polysaccharide involvement in establishing the rhizobium-legume symbiosis. Eur. J. Biochem. 270:1365-1380.

Gage, D. J. 2004. Infection and invasion of roots by symbiotic, nitrogenfixing rhizobia during nodulation of temperate legumes. Microbiol. Mol. Biol. Rev. 68:280-300.

Griffitts, J. S., Carlyon, R. E., Erickson, J. H., Moulton, J. L., Barnett, M. J., Toman, C. J., and Long, S. R. 2008. A Sinorhizobium meliloti osmosensory two-component system required for cyclic glucan export and symbiosis. Mol. Microbiol. 69:479-490.

Haag, A. F., Wehmeier, S., Beck, S., Marlow, V. L., Fletcher, V., James, E. K., and Ferguson, G. P. 2009. The Sinorhizobium meliloti LpxXL and AcpXL proteins play important roles in bacteroid development within alfalfa. J. Bacteriol. 191:4681-4686.

Haag, A. F., Wehmeier, S., Muszyński, A., Kerscher, B., Fletcher, V., Berry, S. H., Hold, G. L., Carlson, R. W., and Ferguson, G. P. 2011. Biochemical characterization of Sinorhizobium meliloti mutants reveals gene products involved in the biosynthesis of the unusual lipid A very long-chain fatty acid. J. Biol. Chem. 286:17455-17466.

Hoang, T. T., Karkhoff-Schweizer, R. R., Kutchma, A. J., and Schweizer, H. P. 1998. A broad-host-range Flp-FRT recombination system for sitespecific excision of chromosomally-located DNA sequences: Application for isolation of unmarked Pseudomonas aeruginosa mutants. Gene 212:77-86.
Jones, K. M., Kobayashi, H., Davies, B. W., Taga, M. E., and Walker, G. C. 2007. How rhizobial symbionts invade plants: The SinorhizobiumMedicago model. Nat. Rev. Microbiol. 5:619-633.

Kannenberg, E. L., and Brewin, N. J. 1989. Expression of a cell surface antigen from Rhizobium leguminosarum 3841 is regulated by oxygen and pH. J. Bacteriol. 171:4543-4548.

Kannenberg, E. L., and Carlson, R. W. 2001. Lipid A and O-chain modifications cause Rhizobium lipopolysaccharides to become hydrophobic during bacteroid development. Mol. Microbiol. 39:379-392.

Kannenberg, E. L., Reuhs, B. L., Forsberg, S., and Carlson, R. W. 1998. Lipopolysaccharides and K-antigens: Their structures, biosynthesis, and function. Pages 119-154 in: The Rhizobiaceae; Molecular Biology of Model Plant-Associated Bacteria. H. P. Spaink, A. Kondorosi, and P. J. J. Hooykaas, eds. Kluwer Academic Publishers, Dordrecht, Boston, London.

Khan, S. R., Gaines, J., Roop, R. M., 2nd, and Farrand, S. K. 2008. Broad-host-range expression vectors with tightly regulated promoters and their use to examine the influence of TraR and TraM expression on Ti plasmid quorum sensing. Appl. Environ. Microbiol. 74:5053-5062.

Kovach, M. E., Elzer, P. H., Hill, D. S., Robertson, G. T., Farris, M. A., Roop, R. M., 2nd, and Peterson, K. M. 1995. Four new derivatives of the broad-host-range cloning vector pBBR1MCS, carrying different antibiotic-resistance cassettes. Gene 166:175-176.

Long, S. R. 2001. Genes and signals in the rhizobium-legume symbiosis. Plant Physiol. 125:69-72.

Manterola, L., Moriyón, I., Moreno, E., Sola-Landa, A., Weiss, D. S., Koch, M. H., Howe, J., Brandenburg, K., and López-Goñi, I. 2005. The lipopolysaccharide of Brucella abortus BvrS/BvrR mutants contains lipid A modifications and has higher affinity for bactericidal cationic peptides. J. Bacteriol. 187:5631-5639.

Melino, V. J., Drew, E. A., Ballard, R. A., Reeve, W. G., Thomson, G., White, R. G., and O'Hara, G. W. 2012. Identifying abnormalities in symbiotic development between Trifolium spp. and Rhizobium leguminosarum bv. trifolii leading to sub-optimal and ineffective nodule phenotypes. Ann. Bot. (Lond.) 110:1559-1572.

Mergaert, P., Nikovics, K., Kelemen, Z., Maunoury, N., Vaubert, D., Kondorosi, A., and Kondorosi, E. 2003. A novel family in Medicago truncatula consisting of more than 300 nodule-specific genes coding for small, secreted polypeptides with conserved cysteine motifs. Plant Physiol. 132:161-173.

Murray, J. D. 2011. Invasion by invitation: Rhizobial infection in legumes. Mol. Plant-Microbe Interact 24:631-639.

Noel, K. D., Vandenbosch, K. A., and Kulpaca, B. 1986. Mutations in Rhizobium phaseoli that lead to arrested development of infection threads. J. Bacteriol. 168:1392-1401.

Nutman, P. S. 1970. Appendix III: The modified Fahraeus slide technique. Pages 144-145 in: A manual for the practical study of root-nodule bacteria. J. M. Vincent, ed. Blackwell Scientific Publications, Oxford, Edinburgh.

Price, N. P., Jeyaretnam, B., Carlson, R. W., Kadrmas, J. L., Raetz, C. R., and Brozek, K. A. 1995. Lipid A biosynthesis in Rhizobium leguminosarum: Role of a 2-keto-3-deoxyoctulosonate-activated 4' phosphatase. Proc. Natl. Acad. Sci. U.S.A. 92:7352-7356.

Raetz, C. R., Reynolds, C. M., Trent, M. S., and Bishop, R. E. 2007. Lipid A modification systems in gram-negative bacteria. Annu. Rev. Biochem. 76:295-329.

Ramadas Bhat, U., Carlson, R. W., Busch, M., and Mayer, H. 1991. Distribution and phylogenetic significance of 27-hydroxy-octacosanoic acid in lipopolysaccharides from bacteria belonging to the alpha-2 subgroup of Proteobacteria. Int. J. Syst. Bacteriol. 41:213-217.

Ramadas Bhat, U., Forsberg, L. S., and Carlson, R. W. 1994. Structure of lipid A component of Rhizobium leguminosarum bv. phaseoli lipopolysaccharide. Unique nonphosphorylated lipid A containing 2-amino-2deoxygluconate, galacturonate, and glucosamine. J. Biol. Chem. 269: 14402-14410.

Reuhs, B. L., Carlson, R. W., and Kim, J. S. 1993. Rhizobium fredii and Rhizobium meliloti produce 3-deoxy-D-manno-2-octulosonic acidcontaining polysaccharides that are structurally analogous to group II $\mathrm{K}$ antigens (capsular polysaccharides) found in Escherichia coli. J. Bacteriol. 175:3570-3580.

Reynolds, E. S. 1963. The use of lead citrate at high $\mathrm{pH}$ as an electronopaque stain in electron microscopy. J. Cell Biol. 17:208-212.

Scheidle, H., Gross, A., and Niehaus, K. 2005. The lipid A substructure of the Sinorhizobium meliloti lipopolysaccharides is sufficient to suppress the oxidative burst in host plants. New Phytol. 165:559-566.

Sharypova, L. A., Niehaus, K., Scheidle, H., Holst, O., and Becker, A. 2003. Sinorhizobium meliloti acpXL mutant lacks the C28 hydroxylated fatty acid moiety of lipid A and does not express a slow migrating form of lipopolysaccharide. J. Biol. Chem. 278:12946-12954. 
Teuber, M., and Bader, J. 1976. Action of polymyxin B on bacterial membranes. Binding capacities for polymyxin B of inner and outer membranes isolated from Salmonella typhimurium G30. Arch. Microbiol. 109:51-58.

Van de Velde, W., Zehirov, G., Szatmari, A., Debreczeny, M., Ishihara, H., Kevei, Z., Farkas, A., Mikulass, K., Nagy, A., Tiricz, H., Satiat-Jeunemaître, B., Alunni, B., Bourge, M., Kucho, K., Abe, M., Kereszt, A., Maroti, G., Uchiumi, T., Kondorosi, E., and Mergaert, P. 2010. Plant peptides govern terminal differentiation of bacteria in symbiosis. Science 327:1122-1126.

Vanderlinde, E. M., Harrison, J. J., Muszyński, A., Carlson, R. W., Turner, R. J., and Yost, C. K. 2010. Identification of a novel ABC transporter required for desiccation tolerance, and biofilm formation in Rhizobium leguminosarum bv. viciae 3841. FEMS Microbiol. Ecol. 71:327-340.

Vanderlinde, E. M., and Yost, C. K. 2012. Genetic analysis reveals links between lipid A structure and expression of the outer membrane protein gene, ropB, in Rhizobium leguminosarum. FEMS Microbiol. Lett. 335:130-139.

Vasse, J., de Billy, F., and Truchet, G. 1993. Abortion of infection during the Rhizobium meliloti-alfalfa symbiotic interaction is accompanied by a hypersensitive reaction. Plant J. 4:555-566.

Vedam, V., Haynes, J. G., Kannenberg, E. L., Carlson, R. W., and Sherrier, D. J. 2004. A Rhizobium leguminosarum lipopolysaccharide lipid-A mutant induces nitrogen-fixing nodules with delayed and defective bacteroid formation. Mol. Plant-Microbe Interact 17:283-291.

Vedam, V., Kannenberg, E., Datta, A., Brown, D., Haynes-Gann, J. G., Sherrier, D. J., and Carlson, R. W. 2006. The pea nodule environment restores the ability of a Rhizobium leguminosarum lipopolysaccharide acpXL mutant to add 27-hydroxyoctacosanoic acid to its lipid A. J. Bacteriol. 188:2126-2133.

Vedam, V., Kannenberg, E. L., Haynes, J. G., Sherrier, D. J., Datta, A., and Carlson, R. W. 2003. A Rhizobium leguminosarum AcpXL mutan produces lipopolysaccharide lacking 27-hydroxyoctacosanoic acid. J. Bacteriol. 185:1841-1850.

Vriezen, J. A. C., de Bruijn, F. J., and Nüsslein, K. 2007. Responses of rhizobia to desiccation in relation to osmotic stress, oxygen, and temperature. Appl. Environ. Microbiol. 73:3451-3459.

Wang, T. L., Wood, E. A., and Brewin, N. J. 1982. Growth regulators, Rhizobium and nodulation in peas: Indole-3-acetic acid from the culture medium of nodulating and non-nodulating strains of $R$. leguminosarum. Planta 155:345-349.

Westphal, O., and Jann, K. 1965. Bacterial lipopolysaccharides: Extraction with phenol-water and further applications of the procedure. Methods Carbohydr. Chem. 5:83-91.

York, W. S., Darvill, A. G., McNeil, M., Stevenson, T. T., and Albersheim P. 1985. Isolation and characterization of plant cell walls and cell wall components. Methods Enzymol. 118:3-40.

Zähringer, U., Knirel, Y. A., Lindner, B., Helbig, J. H., Sonesson, A., Marre, R., and Rietschel, E. T. 1995. The lipopolysaccharide of Legionella pneumophila serogroup 1 (strain Philadelphia 1): Chemical structure and biological significance. Prog. Clin. Biol. Res. 392: 113-139. 